\title{
脱烯丙基反应研究进展
}

\author{
王 宇 ${ }^{\dagger}, a$ 王泾洋 ${ }^{\dagger}, a$ 吴啸宇 $a$ 丁广妮 ${ }^{b}$ 张兆国*,a 谢小敏 $*, a$ \\ ( ${ }^{a}$ 上海交通大学化学化工学院 上海 200240) \\ ( $b$ 南昌大学材料科学与工程学院 南昌 330031)
}

\begin{abstract}
摘要 烯丙基是有机合成中常用的保护基团, 具有引入简单, 在酸碱性及还原剂等条件下稳定, 在相对温和的条件下 选择性地脱保护等特点, 在有机合成特别是药物和天然产物的合成研究中具有重要地位. 近几十年来, 研究者们对各 类烯丙基的脱保护方法进行了广泛研究. 按碱及还原剂促进、氧化及自由基过程、路易斯酸促进、碘促进、过渡金属 催化及电化学方法等分类, 对脱烯丙基保护方法的研究进展进行了综述.

关键词 脱烯丙基反应; 碱促进脱烯丙基化; 过渡金属催化脱烯丙基化; 氧化脱烯丙基化; 自由基历程脱烯丙基化; 路 易斯酸催化脱烯丙基化; 电化学脱烯丙基化
\end{abstract}

\section{Advances in Deallylation}

\author{
Wang, $\mathrm{Yu}^{\dagger, a} \quad$ Wang, Jingyang ${ }^{\dagger, a} \quad$ Wu, Xiaoyu ${ }^{a} \quad$ Ding, Guangni ${ }^{b}$ \\ Zhang, Zhaoguo*,a Xie, Xiaomin*,a \\ ( ${ }^{a}$ School of Chemistry and Chemical Engineering, Shanghai Jiao Tong University, Shanghai 200240) \\ ( ${ }^{b}$ School of Materials Science and Engineering, Nanchang University, Nanchang 330031)
}

\begin{abstract}
Allyl groups, as a kind of universal protective groups in organic synthesis, are easily introduced, and stable under acidic, basic and reductive conditions. Moreover, the deallylation may occur efficiently and selectively under mild conditions. Therefore, functional group protection with allyl moiety plays a significant role in organic synthesis, especially in the synthesis of natural products and pharmaceutical industry. In recent decades, various methods of deallylation have been developed. Herein, the comprehensive development on the deallylation reaction with base and reductant, oxidation and free radical, Lewis-acid, iodine, transition metals, and electrochemical methods is reviewed.

Keywords deallylation; base-catalyzed deallylation; transition metal catalyzed deallylation; oxidative deallylation; free radical deallylation; Lewis-acid catalyzed deallylation; electrochemical deallylation
\end{abstract}

官能团的保护及脱保护是有机合成中重要的步骤. 尤其是羟基、氨基及羧基等活性官能团广泛存在于天然 产物、药物及材料等有机分子中, 这些官能团的保护和 脱保护是多官能团化合物合成中常用的策略 ${ }^{[1]}$. 其中烯 丙基是这些官能团的最常用的保护基之一[2]. 主要由于 其具有以下优点: 烯丙基保护的试剂容易获得, 通常使 用的烯丙基化试剂为烯丙基卤代烃、烯丙基醇或烯丙基 酯等; 可以以较高的产率得到相应的保护产物; 烯丙基 保护的官能团在酸性、碱性以及还原剂等条件下具有一
定的稳定性; 相对于烷基保护，烯丙基保护基可以在比 较温和的条件下脱除; 在其他保护基团及官能团存在下 可以选择性地脱除; 并且脱除部分容易除去等. 此外, 近年来，脱烯丙基反应开始被应用到药物及材料合成中 残留金属的检测及药物在生物体内的缓释等技术中 ${ }^{[3]}$. 因此发展简单、温和、高效且快速的脱烯丙基方法被广 泛关注. 本文按照碱及还原剂促进、氧化及自由基过程、 路易斯酸促进、碘促进、过渡金属催化及电化学方法等 分类对脱烯丙基保护方法的研究进展进行系统综述.

\footnotetext{
* Corresponding authors. E-mail: zhaoguo@sjtu.edu.cn; xiaominxie@sjtu.edu.cn

Received September 13, 2020; revised October 28, 2020; published online November 18, 2020.

Project supported by the National Natural Science Foundation of China (No. 21672143) and the Interdisciplinary Program of Shanghai Jiao Tong University (No. YG2017MS26).

国家自然科学基金(No.21672143)及上海交通大学医工交叉(No. YG2017MS26)资助项目.

$\dagger$ 共同第一作者(These authors contributed equally to this work).
} 


\section{1 碱及还原剂促进的脱烯丙基反应}

\section{1 碱促进的脱烯丙基反应}

有机化合物中的含氧、氮等杂原子官能团被烯丙基 保护后形成烯丙基醚、烯丙基胺等结构单元, 碳一碳双键 和具有一定活性的亚甲基的引入, 为这类保护基的脱除 提供了更多的方式. 其中利用烯丙基醚中碳一碳双键和 氧原子中间的亚甲基上氢的弱酸性，在适当的条件下发 生烯烃异构化, 将烯丙基醚异构化为容易脱除的烯醇醚 来实现脱烯丙基, 是一类重要的脱烯丙基方法. 1961 年, Prosser ${ }^{[4]}$ 报道了使用催化量的强碱叔丁醇钾在较高温度 下可以使烯丙基醚化合物异构化为相应的烯醇醚, 然后 将烯醇醚水解从而可以得到脱烯丙基化的醇/酚(Scheme 1). 同年, Price 等 ${ }^{[5]}$ 将此法进行了改进, 将原本的无溶剂 条件优化为使用二甲基亚砜(DMSO)作为反应的溶剂, 可以降低烯丙基醚的异构化的温度, 快速地发生异构化.

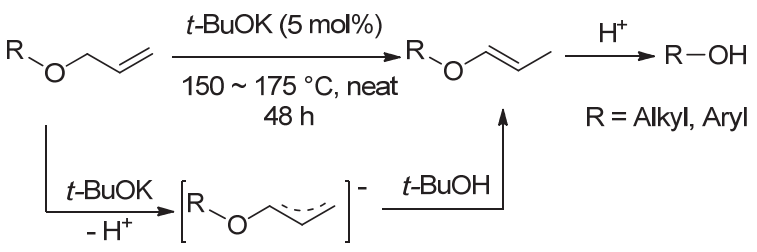

图式 1 碱促进的异构化脱烯丙基化反应

Scheme 1 Base promoted deallylation reaction via isomerization

此后，碱催化烯丙基醚异构化体系得到了广泛的关 注与发展. 碱催化的脱烯丙基反应通常经历两步来实 现. 第一步使用叔丁醇钾促进烯丙基醚异构化为相应的 烯醇醚, 第二步将烯醇醚转化为脱保护的醇/酚产物. 碱 催化的烯丙基醚脱烯丙基反应的研究主要集中在第二 步中，根据底物性质以及官能团兼容性的不同，逐渐发 展出许多不同的脱烯丙基反应体系. 按照反应原理大致 可分为水解体系与氧化体系. 水解体系使用的试剂主要 有 (1) $\mathrm{HCl}$, 丙酮/水 ${ }^{[6]} ;$ (2) $\mathrm{BF}_{3} \cdot \mathrm{Et}_{2} \mathrm{O}, \mathrm{Bu}_{4} \mathrm{~N}^{+} \mathrm{F}^{-[7]} ;$ (3) $\mathrm{TsOH}, \mathrm{MeOH}^{[8]}$; (4) $\mathrm{HgCl}_{2} / \mathrm{HgO}^{[9]}$; (5) NIS, $\mathrm{CH}_{2} \mathrm{Cl}_{2}$, $\mathrm{H}_{2} \mathrm{O}^{[10]} ;(6) \mathrm{PdCl}_{2}, \mathrm{CuCl}_{2}, \mathrm{H}_{2} \mathrm{O}^{[11]}$ 等. 氧化体系主要有(1) 碱性 $\mathrm{KMnO}_{4}{ }^{[12]}$; (2)臭氧化体系 ${ }^{[13]} ;$ (3) $\mathrm{SeO}_{2}, \mathrm{H}_{2} \mathrm{O}_{2}{ }^{[14]}$; (4) $\mathrm{Me}_{3} \mathrm{NO}, \mathrm{OsO}_{4}{ }^{[15]} ;(5) \mathrm{mCPBA}^{[16]}$ 等.

这些脱烯丙基的反应被广泛地应用到天然产物及 药物分子的合成中. 1997 年, Effenberger 等 ${ }^{[17]}$ 在研究肾 上腺素支气管扩张剂 $(R)$-Terbutaline 和 $(R)$-Salbutamol 的 制备时，脱烯丙基保护的步骤采用了催化量的强碱 $t$-BuOK 在 DMSO 作溶剂的条件下与底物芳基烯丙基醚 共热反应 $16 \mathrm{~h}$, 底物芳基烯丙基梄先以较高产率选择性 地被异构化为顺式的烯醇醚, 烯醇醚再在温和的酸性条 件下被水解为脱保护后的酚产物. 作者也尝试了 $\mathrm{PdCl}_{2}$,
$\mathrm{Pd} / \mathrm{C}, \mathrm{Pd}(\mathrm{OAc})_{2} / \mathrm{PPh}_{3}$ 等钯催化的脱烯丙基体系，均不适 用于其合成中间体的脱烯丙基. 此外，作者指出采用碱 催化异构化体系得到的产物的立体构型得以保留，且可 以通过重结晶方式对产物进行纯化(Scheme 2).

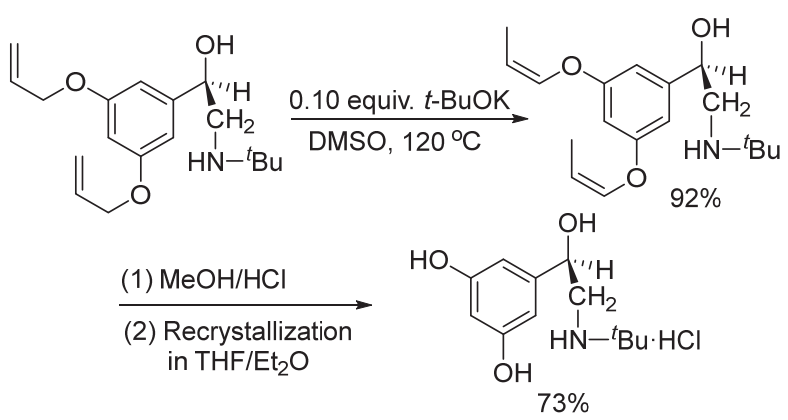

图式 2 碱催化的脱烯丙基化合成 $(R)$-Terbutaline Scheme 2 Synthesis of $(R)$-Terbutaline via base-catalyzed deallylation

\section{2 还原剂促进的烯丙基反应}

除了 $t$ - $\mathrm{BuOK}$, 其他的碱或还原剂应用于脱烯丙基 反应也被陆续报道. 1976 年, Kametani 等 ${ }^{[18]}$ 在合成喷他 佐辛(Pentazocine)时发现 $\mathrm{NaAlH}_{2}\left(\mathrm{OCH}_{2} \mathrm{CH}_{2} \mathrm{OCH}_{3}\right)_{2}$ 在二 甲苯作溶剂、回流的条件下，可以使二取代烯丙基或苄 基保护的酚类化合物发生脱烯丙基或脱苄基反应，得到 相应的酚(Eq. 1). 当底物中同时存在烯丙基保护的胺类 和酚类化合物时, $\mathrm{NaAlH}_{2}\left(\mathrm{OCH}_{2} \mathrm{CH}_{2} \mathrm{OCH}_{3}\right)_{2}$ 可以选择性 地与烯丙基醚反应发生脱烯丙基化，而烯丙基胺结构可 以保留。

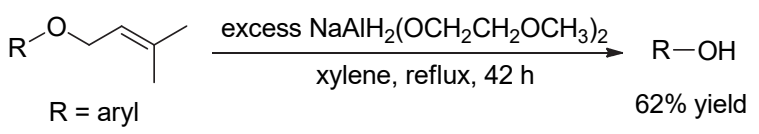

1997 年, Iyengar 课题组 ${ }^{[19]}$ 采用 $\mathrm{NaBH}_{4} / \mathrm{I}_{2}$, 以四氢呋 喃(THF)作溶剂, 在较温和的反应条件下实现了醚类化 合物的脱烯丙基化(Eq. 2). 该方法对烷基烯丙基醚、芳 基烯丙基醚都适用，且能兼容氰基、酯基和酮羰基等易 被还原的官能团. 在反应体系中，可以检测到少量烯烃 硼氢化副产物。

$$
\mathrm{R}=\text { aryl, alkyl } \stackrel{\begin{array}{c}
0.13 \text { equiv. } \mathrm{NaBH}_{4} \\
0.05 \text { equiv. } \mathrm{I}_{2}
\end{array}}{0^{\circ} \mathrm{C}, \mathrm{THF},<1 \mathrm{~h}} \mathrm{R}-\mathrm{OH}
$$

由于 $\mathrm{NaBH}_{4} / \mathrm{I}_{2}$ 在 $\mathrm{THF}$ 作为溶剂时，常常会产生乙 硼烷，作者认为 $\mathrm{NaBH}_{4}$ 促进的脱烯丙基反应很可能是 体系内形成的硼烷与醚上氧原子发生配位后，经历一个 六元环化过渡态来实现脱烯丙基(图 1). 作者通过使用 $\mathrm{BH}_{3} \bullet \mathrm{Me}_{2} \mathrm{~S}$ 在 $\mathrm{THF}$ 溶剂中也可以实现脱烯丙基化来证实 
了关于中间体的推测。

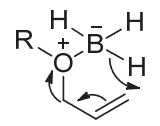

图 $1 \mathrm{NaBH}_{4}$ 促进脱烯丙基化过程中可能形成的六元环过渡 态

Figure 1 Possible transition state in deallylation reaction with $\mathrm{NaBH}_{4}$

2003 年, 李春葆等 ${ }^{[20]}$ 报道了 $\mathrm{BF}_{3}$ 存在下 $\mathrm{NaBH}_{4}$ 促 进芳基烯丙基醚脱烯丙基保护的体系(Eq. 3). 使用 1.2 equiv. 的 $\mathrm{NaBH}_{4}$ 及 $\mathrm{BF}_{3}$ 作为 Lewis 酸, 在无水 $\mathrm{THF}$ 中反 应, 反应完全后使用甲醇进行淬灭得到相应的脱烯丙基 化产物.

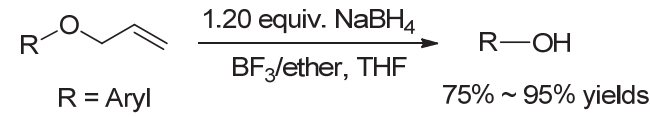

2009 年, Lokhande 课题组 ${ }^{[21]}$ 报道了以 $\mathrm{NaBH}_{4}$ 为还 原剂的烯丙酯的脱烯丙基保护方法. 使用 2 equiv. 的 $\mathrm{NaBH}_{4}$ 为还原剂, DMSO 作为溶剂, 在室温下反应 10 $25 \mathrm{~h}$, 可有效脱除烯丙酯的烯丙基保护得到相应的羧酸 (Eq. 4). 在该反应体系中脂肪烯丙酯的反应活性低于芳 香烯丙酯. 该反应体系对于氨基、硝基、氯原子和溴原 子等官能团显示出很好的兼容性. 然而, 该体系并不能 实现芳香烯丙基醚的脱烯丙基保护，同时，底物中含有 醛基时，醛基会被还原.

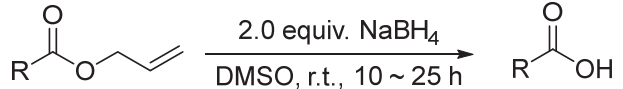

$$
\begin{aligned}
& \mathrm{R}=\text { alkyl, aryl } \quad 76 \% \sim 92 \% \text { yields }
\end{aligned}
$$

\section{3 有机锂试剂促进的脱烯丙基反应}

1965 年, Mann 等 ${ }^{[22]}$ 在研究二苯基膦阴离子对芳基 烷基醚的去烷基化作用时, 发现由叔丁基锂的石油醚溶 液与二苯基膦氢反应生成的 $\mathrm{LiPPh}_{2}$, 在 $\mathrm{THF}$ 中与芳基 烯丙基醚共热回流，可以以 78\%的产率得到脱烯丙基化 目标产物酚(Eq. 5). 当底物为芳基甲基醚或芳基苠基醚 时，使用该体系也会发生脱甲基或茮基反应.

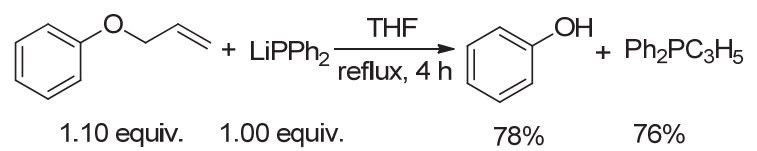

2000 年, Bailey 等 ${ }^{[23]}$ 报道了使用 1.1 equiv. 叔丁基锂 在烃类溶剂中可以实现烯丙基醚脱烯丙基得到相应醇 或酚(Eq. 6). 该体系对于一级、二级、三级的脂肪烯丙 基醚及芳基烯丙基醚，都能以大于 $90 \%$ 的产率得到脱烯 丙基保护的产物. 此外, 该方法对于具有苄基、(半)缩醛
和硅基的底物具有很好的官能团兼容性.

$$
\begin{aligned}
& \text { (1) }{ }^{t} \mathrm{BuLi} \text {, pentane } \\
& \mathrm{RO} \curvearrowright \underset{(2) \mathrm{H}^{+}}{\stackrel{-78{ }^{\circ} \mathrm{C} \sim \text { ambient, } 1 \mathrm{~h}}{\longrightarrow}} \mathrm{ROH}+ \\
& \mathrm{R}=\text { alkyl, aryl } \quad 89 \% \sim 99 \% \text { yields }
\end{aligned}
$$

烯丙基醚与有机锂试剂反应的过程中通常为有机 锂试剂先对烯丙基醚的烯丙位的碳进行脱质子化生成 $Z$-构象的烯丙氧基有机金属物种; 该中间体在较低温度 下可接受亲电试剂的进攻形成易于水解的烯醇醚，而在 较高温度下倾向于生成 $[1,2]$ 或 $[1,4]$-Wittig 重排产物. Bailey 等认为在该脱烯丙基方法中叔丁基锂先与烯丙基 醚上的氧配位形成环状过渡态，经过 $\mathrm{S}_{\mathrm{N}} 2^{\prime}$ 反应形成叔丁 基取代的烯烃及烷氧基锂盐，再酸化处理后最终生成 碳一氧键断裂的脱烯丙基产物和一分子的烯烃(Scheme 3). 因此反应体系所使用的溶剂非常重要，作者通过对 照实验发现，使用正戊烷作为溶剂最有利于脱保护产物 的生成.

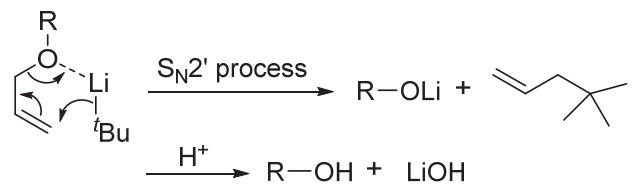

图式 3 有机锂试剂促进脱烯丙基反应可能反应历程 Scheme 3 Possible reaction pathway of deallylation reaction with ${ }^{t} \mathrm{BuLi}$

2008 年, Sanz 等 ${ }^{[24]}$ 也通过使用丁基锂作为脱烯丙基 化试剂发展了针对邻位具有甲氧基取代的芳环烯丙基 醚选择性脱烯丙基保护的体系(Scheme 4). 对氟、氯等 取代的邻位具有甲氧基的芳环烯丙基醚均可以以较高 的产率得到相应的脱烯丙基的产物，但该方法对于溴代 底物不兼容. 此外，当芳基烯丙基醚的甲氧基不在邻位 时，则不能有效地实现脱烯丙基保护. 作者通过一系列 的氝代实验，探究了邻位甲氧基对选择性脱烯丙基的影 响一一如果邻位没有甲氧基，底物则先经去质子化得到

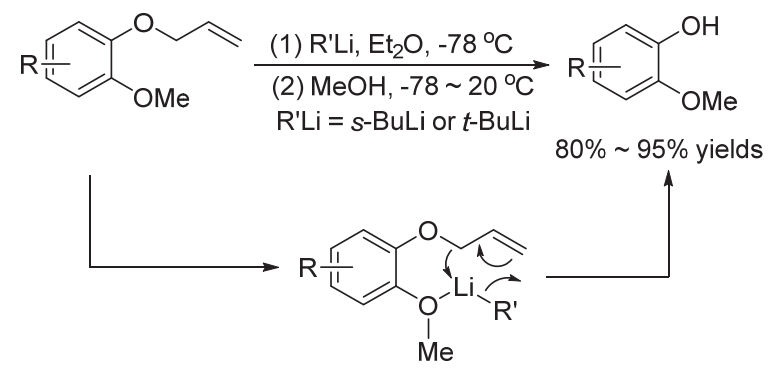

图式 4 丁基锂促进的邻位具有甲氧基的芳基烯丙基醚的脱 烯丙基化反应

Scheme 4 Deallylation of aryl allyl ethers with ortho-methoxy group promoted by butyl lithium 
烯丙基锂中间体, 再进一步生成 [1,2]或[1,4]-Wittig 重排 的混合产物. 作者认为, 该反应体系具有此选择性的原 因是邻位甲氧基与有机锂试剂的配位作用会有利于其 接近碳一碳双键, 从而推动脱烯丙基反应的发生.

\section{4 金属锂促进的脱烯丙基反应}

1997 年, Yus 课题组 ${ }^{[25]}$ 报道了金属锂促进的还原脱 烯丙基化反应. 在 $\mathrm{Li}$ 粉存在的条件下, 使用催化量的荎 以 THF 作溶剂, 低温反应可以脱去芐基、烯丙基和磺酰 基保护. 当底物为被保护的醇、酚、胺或酰胺时, 该体 系均表现出较好的适用性(Eqs. 7,8). 当该体系应用于 醚类化合物的脱保护时, 芐基的脱保护要优于脱烯丙 基.
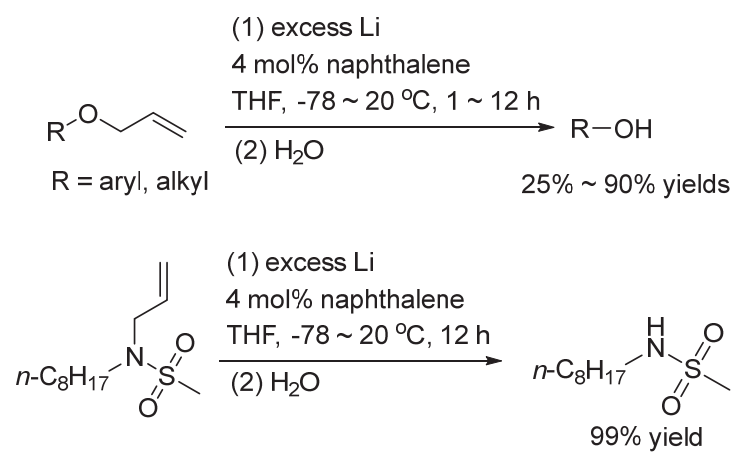

\section{2 氧化及自由基过程脱烯丙基反应}

烯丙基保护氧、氮等杂原子的结构单元中碳一碳双 键和杂原子中间的亚甲基对于氧化剂或活性自由基具 有一定的反应活性，通过对烯丙基结构中的亚甲基氧化 或自由基反应也是实现脱烯丙基的一类重要方法.

\section{1 氧化脱烯丙基反应}

1970 年, Kariyone 等 ${ }^{[26]}$ 使用 $\mathrm{SeO}_{2}$, 在 $\mathrm{AcOH}$ 存在的 条件下, 用二氧六环作溶剂, 通过氧化一步实现了芳基 烯丙基醚脱烯丙基化, 得到相应的酚产物与一分子丙烯 醛(Eq. 9). 由于烯丙基醚转化不完全, 脱烯丙基化的产 率在 38\% 57\% 之间. 该方法对芳基烯丙基醚芳环上的 三氟甲基、卤素、甲氧基、硝基和酯基等官能团均有良 好的兼容性.

$$
\begin{aligned}
& \mathrm{R}^{-} \curvearrowright \frac{\begin{array}{l}
1.10 \text { equiv. } \mathrm{SeO}_{2} \\
1.50 \text { equiv. } \mathrm{AcOH}
\end{array}}{\text { dioxane, reflux, } 1 \mathrm{~h}} \mathrm{R}-\mathrm{OH}+\stackrel{\mathrm{O}}{\sim} \\
& \mathrm{R}=\text { aryl, benzyl } \quad 38 \% \sim 57 \% \text { yields }
\end{aligned}
$$

$\mathrm{SeO}_{2}$ 通常可以氧化酚类化合物, 但在该体系中, 并 未检测到酚被氧化后得到的产物. 针对该反应的路径, 作者推测底物芳基烯丙基醚会先被 $\mathrm{SeO}_{2}$ 氧化得到丙烯 醛的半缩醛中间体, 再经过水解实现脱烯丙基化
(Scheme 5).

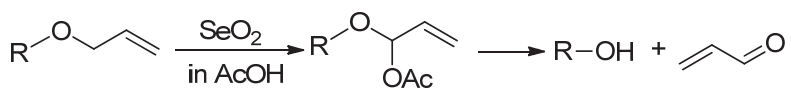

图式 $5 \mathrm{SeO}_{2}$ 脱烯丙基化反应的反应历程

Scheme 5 Reaction pathway of deallylation with $\mathrm{SeO}_{2}$

1992 年, Choudary 等 ${ }^{[27]}$ 报道使用催化量的铬柱式蒙 脱石(Chromium-pillared montmorillonite)和等物质的量 的过氧化叔丁醇, 通过氧化反应高效地实现烯丙基醚或 烯丙基胺的选择性脱烯丙基反应(Scheme 6). 在这个反 应中, 对于不同的反应底物, 需要使用 $t-\mathrm{BuOOH}$ 的物质 的量不同. 当底物为烷基烯丙基醚时，使用催化量的 Cr-PILC 和 1 equiv. 的 $t$-BuOOH, 在干燥的二氯甲烷作溶 剂的条件下反应，可得到对应的脱烯丙基保护后的醇; 对于芳基烯丙基醚及烷基烯丙基胺的脱烯丙基化，则必 须加入 2 equiv. 的 $t$ - $\mathrm{BuOOH}$ 才能得到脱保护后的酚或胺 类产物. 对于该体系的氧化原理, 作者推测 Cr-PILC 中 的金属铬中心以 III 价态形式存在的，如果仅使用等物 质的量的 Cr-PILC, 该体系并不能实现烯丙位氧化或氧 化脱烯丙基化, 从而说明 $\mathrm{Cr}$ (III)是氧化惰性的. 为了提 高 $\mathrm{Cr}$ 的氧化数使其具有氧化活性, 就需要加入 1.2 倍 物质的量的外源氧化剂(如 $t-\mathrm{BuOOH}$ )来持续推动催化氧 化循环.

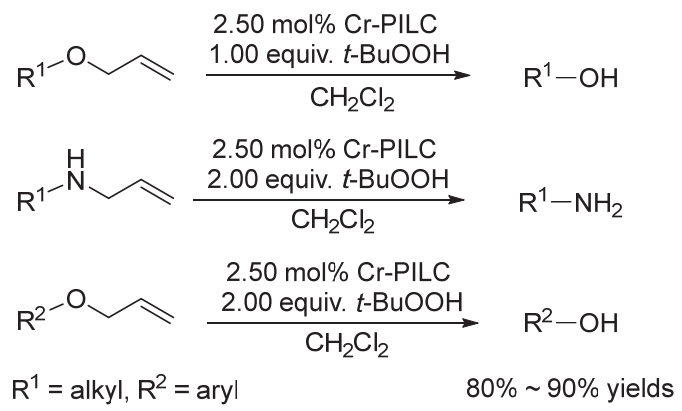

图式 6 铬(III)催化的脱烯丙基化反应

Scheme 6 Deallylation catalyzed by chromium(III)

1996 年, Yadav 等 ${ }^{[28]}$ 报道了使用 1.2 equiv.的 2,3-二 氯- 5,6-二㲵基对苯醌(DDQ)、二氯甲烷和水作为混合溶 剂, 一步氧化实现烷基烯丙基醚的脱烯丙基保护的方 法. 该方法对酯基、碳一碳双键和含硅保护基都有良好的 官能团兼容性, 然而, 该方法只适用于脱去一级烷基醇 的烯丙基保护(Eq. 10), 若底物为二级醇或糖类化合物 的异头碳上的羟基被保护后形成的烯丙基醚, 则该脱烯 丙基化体系不能适用. 当苄基醚和糖类化合物异头碳烯 丙基醚共存时，该体系会选择性地脱去芐基保护.

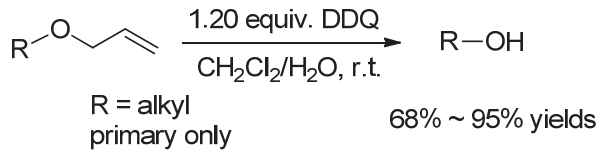


作者提出了可能的反应机理：烷基烯丙基醚的烯丙 基被 DDQ 氧化为烯丙基正离子, 然后被水进攻得到半 缩醛类化合物, 再经过水解得到脱烯丙基产物(Scheme 7).

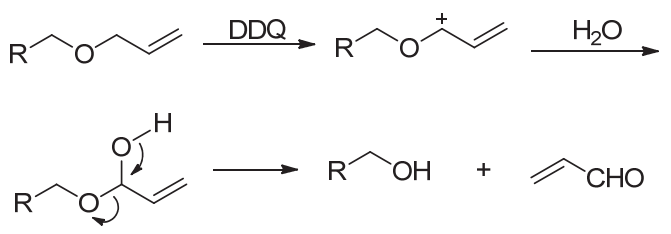

图式 $7 \mathrm{DDQ}$ 氧化脱烯丙基化的反应机理

Scheme 7 Mechanism of the oxidative deallylation with DDQ

2014 年, Kumar 等 ${ }^{[29]}$ 报道了 DDQ 氧化体系在室温 条件下以较高的产率实现三级胺类化合物的脱烯丙基 反应(Eq. 11). 烯丙基保护的脂肪胺、脂环胺及芳香胺在 该体系下都能以较高的产率实现脱烯丙基保护. 并且该 体系对其他氨基保护基团有良好的兼容性(芐基、叔丁 氧羰基、对甲苯磺酰基、对甲氧基芐基). 当反应底物中 同时含有烯丙基叔胺和伯烷基烯丙基醚，使用该氧化体 系这两个结构单元都可以脱保护; 而底物中若同时含有 烯丙基叔胺和仲烷基烯丙醚, 则可实现选择性地脱去烯 丙胺的烯丙基保护而烯丙醚保持不变.

$$
\begin{aligned}
& \mathrm{R}_{\mathrm{R}_{1}^{1}}^{\mathrm{R}^{2}} \\
& \mathrm{R}^{1}=\mathrm{alkyl} ; \mathrm{R}^{2}=\text { alkyl, aryl; } \\
& \mathrm{R}^{3}, \mathrm{R}^{4}=\mathrm{H}, \mathrm{Me}, \mathrm{Ph}
\end{aligned}
$$

该氧化方法脱胺类化合物的烯丙基保护的机理类 似于 DDQ 脱烯丙基醚类化合物的烯丙基的过程: 首先 DDQ 将烯丙基叔胺氧化为亚胺正离子, 然后亚胺离子 与水作用生成半胺醛中间体, 水解后得到相应的二级胺 和等物质的量的丙烯醛.

\section{2 自由基过程的脱烯丙基反应}

1994 年, Robles Diaz 等 ${ }^{[30]}$ 使用 $N$-溴代丁二酰亚胺 (NBS), 借助光催化将烯丙位选择性地溴化, 得到 $\alpha$ 位 被溴代的烯丙基醚后, 再在碱性条件下水解得到脱烯丙 基化后的醇产物(Eq. 12). 针对不同类型或带有不同取 代基的底物, 水解的条件会有所不同, 可以采用 $\mathrm{NaOH}$ 、 $\mathrm{NaHCO}_{3}$ 或硅胶等. 当被保护的羟基为一级醇、二级醇 或为糖类化合物的异头碳上的羟基时, 该体系均能高效 地脱去其烯丙基保护，且该体系对苯甲酰基和乙酰基具 有一定的兼容性. 作者提出了该脱烯丙基化反应的反应 历程(Scheme 8).

$$
\begin{aligned}
& \text { (1) } 1.00 \text { equiv. NBS }
\end{aligned}
$$

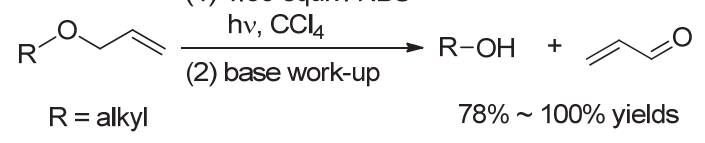

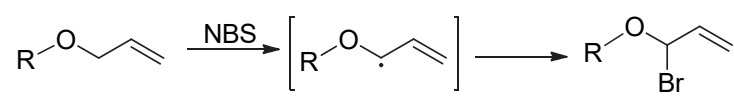

$$
\begin{aligned}
& \underset{\text { base }}{\stackrel{\mathrm{H}_{2} \mathrm{O}}{\longrightarrow}} \mathrm{R}-\mathrm{OH}+\underset{\mathrm{O}}{\sim} \mathrm{O}
\end{aligned}
$$

图式 $8 \mathrm{NBS}$ 在光催化条件下脱烯丙基化的反应历程 Scheme 8 Reaction pathway of light-catalyzed deallylation with NBS

2002 年, Kim 课题组 ${ }^{[31]}$ 发展一种使用过硫酸四丁基 铵 $\left[(\mathrm{TBA})_{2} \mathrm{~S}_{2} \mathrm{O}_{8}\right]$ 及碘分子作为活化试剂的烯丙基醚脱烯 丙基方法. 使用乙腈/水作为混合溶剂, 在接近中性的条 件下，25 50 ${ }^{\circ} \mathrm{C}$ 反应，生成相应的脱烯丙基的醇或酚 (Eq. 13). 该方法的脱保护反应条件较温和，广泛适用于 一级/二级/三级脂肪烯丙基醚, 并且可以兼容一些敏感 的官能团, 例如有对酸性或氧化还原敏感的苠基、苯甲 酸酯、四氢吡喃、叔丁基二苯基硅基(TBDPS)、半缩醛、 内酯和醛基等结构. 其中, 过硫酸四丁基铵可由四丁基 亚硫酸氢铵与过硫酸钾现场发生交换反应生成. 作者发 现乙腈/水 $(V: V=10: 1)$ 的混合溶剂效果最佳, 加入 1.0 equiv. 的碘分子作为活化试剂能使反应产率从 $72 \%$ 升至 93\%. 而当底物为被烯丙基保护的 $\beta$-呋喃糖时, 在脱烯 丙基反应过程中会发生消旋化.

$$
\begin{aligned}
& \underset{R=\text { alkyl }}{-O}+\mathrm{Bu}_{4} \mathrm{~N}^{+-} \mathrm{O}-\mathrm{S}_{\mathrm{O}}^{\mathrm{O}}-\mathrm{O}-\mathrm{O}-\mathrm{S}_{\mathrm{O}}^{\mathrm{O}}-\mathrm{O}^{-+} \mathrm{NBu}_{4} \frac{\mathrm{I}_{2}, \mathrm{CH}_{3} \mathrm{CN} / \mathrm{H}_{2} \mathrm{O}}{25 \sim 50^{\circ} \mathrm{C}} \\
& \mathrm{R}-\mathrm{OH}+\mathrm{OHC} \\
& 81 \% \sim 95 \% \text { yields }
\end{aligned}
$$

作者提出该体系下的脱烯丙基保护过程是经历了 烯丙基自由基中间体 $\mathbf{B}$, 即过硫酸四丁基铵首先发生均 裂生成自由基 $\mathbf{A}, \mathbf{A}$ 捕获烯丙基醚底物中的氢形成相对 比较稳定的烯丙基自由基中间体 $\mathbf{B}, \mathbf{B}$ 再与前一步均裂 生成的另一分子自由基 $\mathbf{A}$ 发生电子转移生成具有共振 结构的烯丙基鎓离子 $\mathbf{C}$, 最后体系中的一分子水和 $\mathbf{C}$ 发 生加成作用生成半缩醛结构 D, D 再发生碳-氧键的断裂 生成脱保护后的醇产物和一分子的醛(Scheme 9).

2003 年, Hilmersson 课题组 ${ }^{[32]}$ 报道了使用 $\mathrm{SmI}_{2}$ / $\mathrm{H}_{2} \mathrm{O} / \mathrm{Et}_{3} \mathrm{~N}$ 或 $\mathrm{SmI}_{2} / \mathrm{H}_{2} \mathrm{O} / i-\mathrm{PrNH}_{2}$ 体系在室温下实现一级 脂肪烯丙基醚、二级脂肪烯丙基醚及芳香烯丙基醚的脱 烯丙基保护的方法(Eq. 14). 该体系能兼容茮基、亚茮 基、硅醚基团及硫代乙基等基团，并且对于糖类化合物 


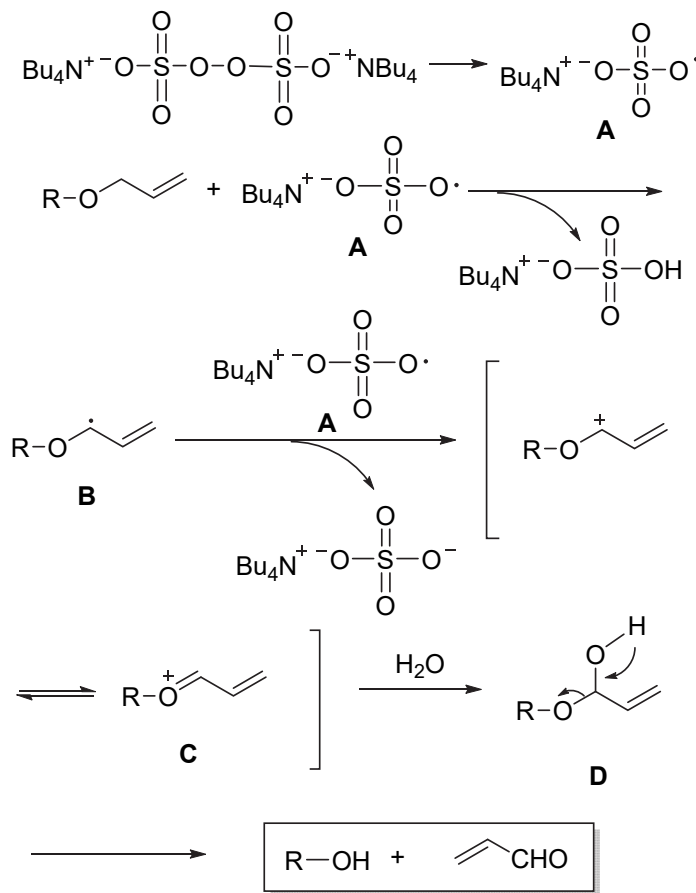

图式 9 过硫酸四丁基铵脱烯丙基化的反应机理

Scheme 9 Mechanism of deallylation with (TBA) ${ }_{2} \mathrm{~S}_{2} \mathrm{O}_{8}$

的异头碳上连接的烯丙氧基也能有效地实现脱烯丙基 保护. 同时, 该体系在脱去烯丙基保护时，不会对底物 原有的立体化学造成影响. 但带有酮羰基、酯基(特别是 $\alpha, \beta$-不饱和酯)或共轭二烯的底物在该反应条件下主要 发生还原反应，而不发生脱烯丙基反应.

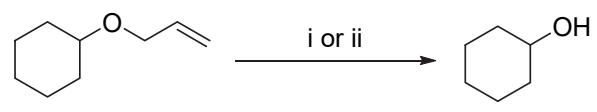

Condition: (i) $\mathrm{Sml}_{2} / \mathrm{H}_{2} \mathrm{O} / \mathrm{Et}_{3} \mathrm{~N}$, r.t., $2 \mathrm{~h}$, > 99\%

Condition: (ii) $\mathrm{Sml}_{2} / \mathrm{H}_{2} \mathrm{O} / \mathrm{i}-\mathrm{PrNH}_{2}$, r.t., 1 min, > $99 \%$

由于异构化与碳-氧键断裂的相对速率会受到烯丙 基附近的烷基环境的影响, 作者对烯丙基的不同碳上连 有烷基取代的底物进行了拓展研究, 结果发现仅对 $\alpha$ 位 被甲基化的烯丙基醚底物，延长反应时间能实现脱保护 生成相应的酚产物，而烯丙基上双键被取代或烯丙基被 延长的底物则不能发生脱保护反应, 这说明烷基取代基 在一定程度上稳定了烯丙基，降低其反应活性. 此外, 若底物是被烯丙基保护的硫醚或胺，该体系不能实现它 们的脱保护. 如果使用烯丙基上双键被异构化即相应的 烯醇醚作为底物, 在该体系下并不能得到脱保护产物, 这一结果说明了 $\mathrm{SmI}_{2} / \mathrm{H}_{2} \mathrm{O} / i-\mathrm{PrNH}_{2}$ 体系并不同于传统的 脱烯丙基保护体系, 而是基于单电子转移过程, 通过一 步反应直接断裂碳一氧键实现的. 作者使用了 $\alpha$ 位被戊 基取代的底物研究反应机理, 用以表征烯丙基自由基在 反应结束时的存在形态. 最终, 在体系中仅监测到正癸
醇和辛烯的存在，而无辛烷或二聚产物. 值得一提的是， 最终产物不仅有 1-辛烯，还有顺反两种 2-辛烯，表明一 定程度上发生了 1,3 -异构化. 因此，作者提出该反应体 系实现脱烯丙基化的机理: 首先体系中的二价钐被氧化 为三价，失去的电子被烯丙基醚底物中的碳一氧键接收, 随后碳一氧键断裂产生的烷氧基阴离子与三价钐配位, 形成的强 Lewis 酸结构可再从水中夺取两个氢氧根形成 饱和的三价钐配合物. 与此同时, 第一步氧化过程中释 放出的两个游离碘离子与剩下的两质子结合，与 $\mathrm{R}_{3} \mathrm{~N}$ 形 成季碘盐沉淀 $\mathrm{R}_{3} \mathrm{~N} \cdot \mathrm{HI}$. 饱和的三价钐配合物再与一分 子水作用，破坏配合物结构得到脱保护的醇产物以及不 溶物 $\mathrm{Sm}(\mathrm{OH})_{3}$. 而断裂碳一氧键过程中形成的具有共振 稳定结构的烯丙基自由基立即与另一对 $\mathrm{SmI}_{2} / \mathrm{H}_{2} \mathrm{O} / \mathrm{R}_{3} \mathrm{~N}$ 发生电子转移作用(氧化二价钐), 得到另一分子的烯 烃、 $\mathrm{Sm}(\mathrm{OH})_{3}$ 以及 $\mathrm{R}_{3} \mathrm{~N} \cdot \mathrm{HI}$ (Scheme 10).

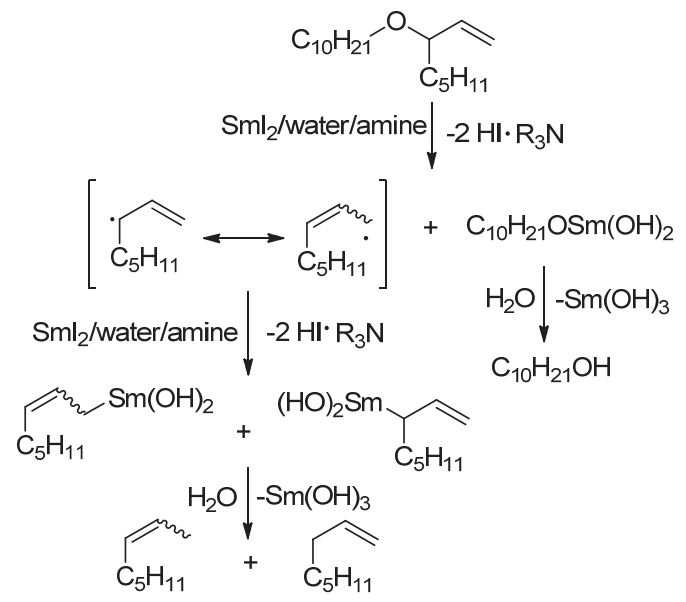

图式 10 碘化矧促进脱烯丙基化的反应机理 Scheme 10 Mechanism of deallylation with $\mathrm{SmI}_{2}$

2004 年, Escoubet 等[33]使用硫醇在偶氮二异丁腈 (AIBN)的作用下实现了胺类化合物的脱烯丙基(Eq. 15). 该反应中 TolSH 作为提供颈基自由基的试剂, AIBN 作 为自由基引发剂, 苯作为溶剂, 在回流温度下, 烯丙基 胺结构异构化为相应的烯胺, 烯胺再在酸性条件下水解 得到脱烯丙基产物. 该反应适用于仲胺及叔胺的脱烯丙 基，且对酯基、苄基等反应活性较高的基团具有良好的 兼容性

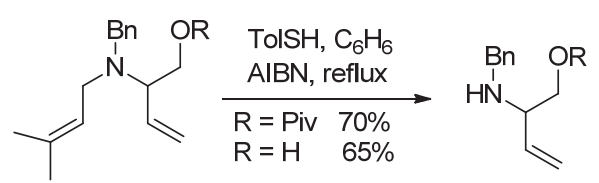

作者通过进一步的实验探究发现，该体系中硫醇不 论以 1.2 equiv.加入还是以催化量( 0.1 或 0.2 equiv.)加入, 都能以较高的产率得到(类)烯丙基胺的脱保护产物. 并 发现该体系在促进(类)烯丙基胺断裂烯丙基碳一氮键得 
到脱保护产物时，反应的活性和效率受到烯丙基的结构 (取代基效应)、被保护的胺中氮原子所连接基团的性质 以及所用硫醇性质的影响, 这些影响可大致分为焓变影 响以及立体电子效应两部分. 最理想的脱保护体系为硫 醇中 $\mathrm{S}-\mathrm{H}$ 键键能强于底物分子中 $\mathrm{C}-\mathrm{H}_{\alpha}$ 键键能但弱于 异构化产物烯胺中 $\mathrm{C}-\mathrm{H}_{\gamma}$ 键键能.

2008 年, Perchyonok 等 ${ }^{[34]}$ 报道了使用质量分数为 10\%的自由基引发剂 $\mathrm{AIBN}$, 在氧气条件下, 水或苯作 为溶剂, $65 \sim 70{ }^{\circ} \mathrm{C}$ 下, 经历自由基过程实现烯丙酯脱烯 丙基保护生成对应的羧酸的方法(Eq. 16).

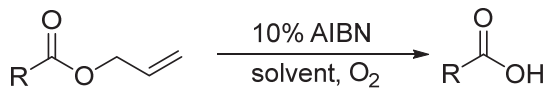

$$
\begin{aligned}
& \mathrm{R}=\text { alkyl, aryl } \quad \begin{array}{r}
65 \% \sim 100 \% \text { yields in } \mathrm{H}_{2} \mathrm{O} \\
86 \% \sim 100 \% \text { yields in benzen }
\end{array}
\end{aligned}
$$

作者提出了该方法的可能机理: AIBN 裂解生成的 异丁腈自由基捕获底物中 $\alpha$ 位的氢, 生成稳定的烯丙基 自由基引发反应, 烯丙基自由基随后与氧气作用生成过 氧自由基; 过氧自由基会从第二分子的底物中捕获氢原 子, 重新生成一分子的氧烯丙基自由基的同时生成过氧 酯类化合物; 紧接着, 该过氧酯易发生分子内的酰基转 移生成相应的酰基过氧化物, 然后在体系中裂解生成一 分子羧酸、一分子丙烯醛和一分子水.

2015, Sawant 课题组 ${ }^{[35]}$ 使用 2 equiv. 的单过硫酸氢 钾 $\left(\mathrm{KHSO}_{5}\right)$ 和 4 equiv. 的三氟乙酸, 在干燥的二氧六环作 溶剂条件下, $90{ }^{\circ} \mathrm{C}$ 反应, 成功实现芳基烯丙基胺或芳基 乙烯基胺的脱保护, 并生成相应的三氟酰基化且芳环的 邻位被羟基取代的产物(Eq. 17). 该方法只适用于芳基 胺类的脱烯丙基保护, 对于脂肪胺类的烯丙基保护不能 实现有效脱除.

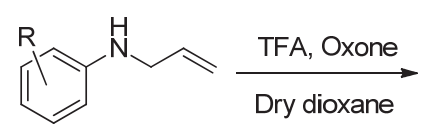

$\mathrm{R}=2-\mathrm{Cl}, 3-\mathrm{Cl}, 4-\mathrm{OMe}$<smiles>[R]c1cccc(O)c1NC(=O)C(F)(F)F</smiles>

$62 \% \sim 69 \%$ yields

\section{3 路易斯酸促进的脱烯丙基反应}

烯丙基醚结构单元与其他的醚类化合物一样, 也可 以在路易斯酸的催化下, 发生烯丙基碳一氧键断裂实现 脱烯丙基反应. 1975 年, Garbers 等[36]在合成萜类化合物 诱雄激素的过程中, 使用 $\mathrm{Ac}_{2} \mathrm{O} / \mathrm{BF}_{3}$ 体系实现了烷基烯 丙基醚中间体的脱烯丙基保护(Scheme 11). 在强路易斯 酸 $\mathrm{BF}_{3}$ 促进下, 底物烯丙基醚脱去烯丙基保护后再乙酰 化，同时生成一分子乙酰烯丙酯. 然后再发生酯交换反 应得到最终脱保护后的醇.

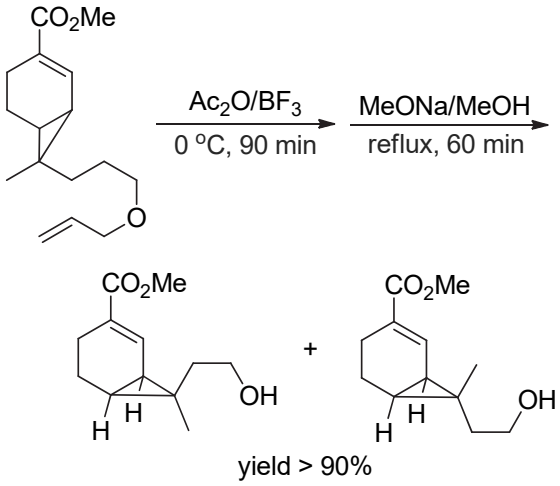

图式 $11 \mathrm{BF}_{3}$ 促进的脱烯丙基化反应

Scheme 11 Deallylation promoted by $\mathrm{BF}_{3}$

1982 年, Bhatt 等 ${ }^{[37]}$ 以二氯甲烷和乙腈作为混合溶 剂, 使用 $\mathrm{SiCl}_{4} / \mathrm{NaI}$ 实现了芳基烯丙基醚的高区域选择 性的脱保护. 该方法也适用于芳基烷基醚的脱烷基化反 应. 当底物中酚羟基同时被烯丙基和甲基保护时，加入 1.1 equiv. 的 $\mathrm{SiCl}_{4} / \mathrm{NaI}$, 该体系会优先进行脱烯丙基化; 如果加入 2.2 equiv. 的 $\mathrm{SiCl}_{4} / \mathrm{NaI}$, 则会生成完全去烷基化 的产物(Eqs. 18, 19).
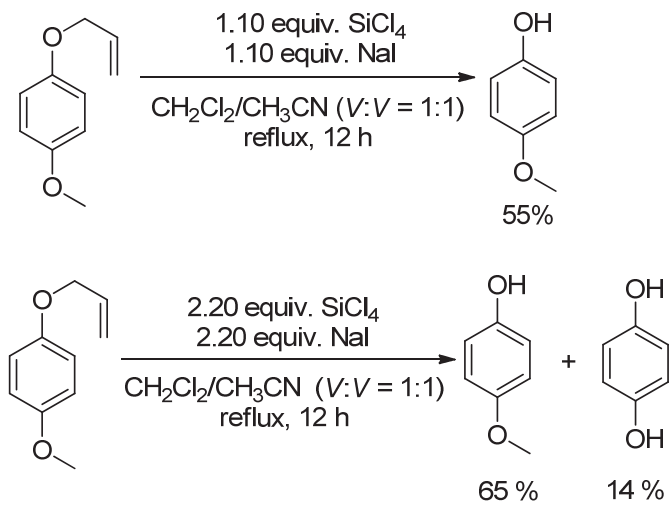

1991 年, Ozaki 课题组 ${ }^{[38]}$ 在探索路易斯酸碱组合体 系的化学活性时, 发展了一种使用 $\mathrm{AlCl}_{3}-\mathrm{PhNMe}_{2}$ 脱烯 丙基的方法. 以二氯甲烷作溶剂, 在室温或回流的条件 下实现了脱烯丙基保护(Eq. 20). 该体系对酯基、碳-碳 双键、硫醚和卤素等具有良好的官能团兼容性, 但该体 系对于醇的烯丙基保护或茮基保护，都可以进行脱保 护. 作者认为该反应的历程为: $\mathrm{AlCl}_{3}$ 先与醚上的氧原子

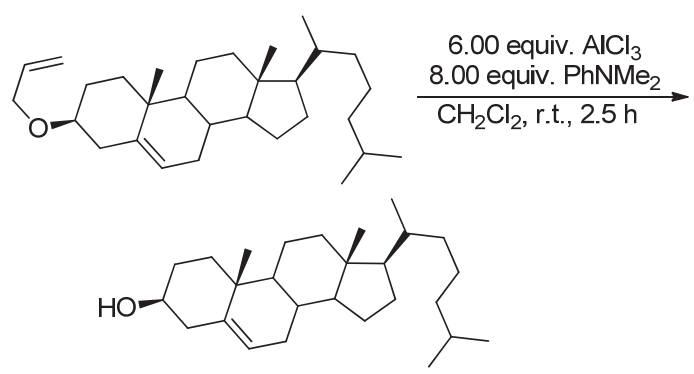


进行配位，然后茮基碳或烯丙基上的碳接受芳香化合物 $\mathrm{PhNMe}_{2}$ 的进攻. 与 $\mathrm{AlCl}_{3}$-苯甲醚体系相比, $\mathrm{PhNMe}_{2}$ 的 亲核性更高, 体系的反应活性更强, 因此可能是通过 $\mathrm{S}_{\mathrm{N}} 2$ 机理进行.

磷铇酸(PWA)具有强的 Brønsted 酸性、质子迁移能 力、无毒性以及较好的稳定性, 近年来常作为一种新型 催化剂取代传统的酸催化剂, 广泛用于各种有机合成反 应中，如烷基化反应、酰基化反应、烯烃的水合反应以 及 THF 的聚合反应等. Rode 课题组 ${ }^{[39]}$ 于 2017 年报道了 一种将 PWA 负载在 MCM-41(一种具有很高比表面积的 有序介孔材料)上，高效完成芳基烯丙基醚脱烯丙基保 护的非均相催化方法(Eq. 21).

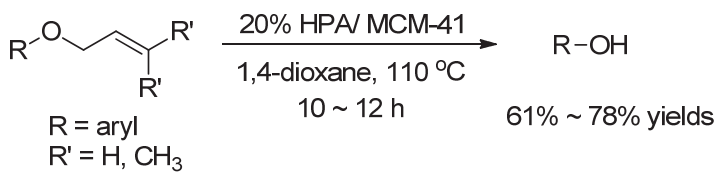

以 $20 \%$ 的负载率将 PWA 负载在 MCM-41 上形成 20\% PWA/MCM-41 异相催化剂(1 mmol 底物加入 100 $\mathrm{mg}$ ), 以二氧六环作为溶剂, 在 $110{ }^{\circ} \mathrm{C}$ 反应, 进行芳基 烯丙基醚的脱保护反应. 带有给电子基团的芳香烯丙基 醚的脱保护产率较高( $70 \% \sim 79 \%$ ), 体系对酸敏感的取 代基(醛、酮)有较好的兼容性，但当底物中存在羰基时， 由于羰基的吸电子作用影响，脱保护产率有所降低 (65\%左右); 而底物中含有强吸电子基团(硝基)时，使用 该方法不能得到相应的脱烯丙基后的酚产物. 此外, 该 体系还适用于芳香异戊二烯醚的脱保护，以 $70 \%$ 的产率 得到相应的酚产物.

作者提出了可能的机理: 首先发生 PWA 向底物芳 基烯丙基醚的质子转移，质子化后的底物再受到 PWA 阴离子的进攻, 发生碳一氧键断裂得到对应的酚产物; 而烯丙基会进一步在体系中被转化为烯丙醇或丙烯，同 时 PWA 催化剂得以再生进入下一催化循环. 此外, 作 者对 20\% PWA/MCM-41 异相催化剂的循环性进行了探 究, 经过三次的催化循环, 酚产率从 $78 \%$ 降至 $67 \%$.

\section{4 磑促进的脱烯丙基反应}

2007 年, Mereyala 课题组 ${ }^{[40]}$ 报道了使用催化量的 $\mathrm{NaI}$, 以 DMSO 作为溶剂, 在 $130{ }^{\circ} \mathrm{C}$ 条件下反应, 实现 芳香烯丙基醚的脱烯丙基保护的方法(Eq. 22). 该体系 对苄基、硝基、羰基和氰基等活性基团具有较好的兼容 性，但当用氨基酸或糖类的烯丙基衍生物作为底物时， 不能通过该方法得到脱保护的产物. 底物为吡啶酮(羟 基吡啶)类化合物时，氮原子上的烯丙基保护基，在该 体系下也能通过断裂碳一氮键得到相应的脱保护吡啶酮
产物(Eq. 23). 此外，对于吡啶酮类底物，当羟基被乙酰 氨基保护时，该体系也能断裂其中的碳-氧键使其水解 得到相应的脱保护产物.

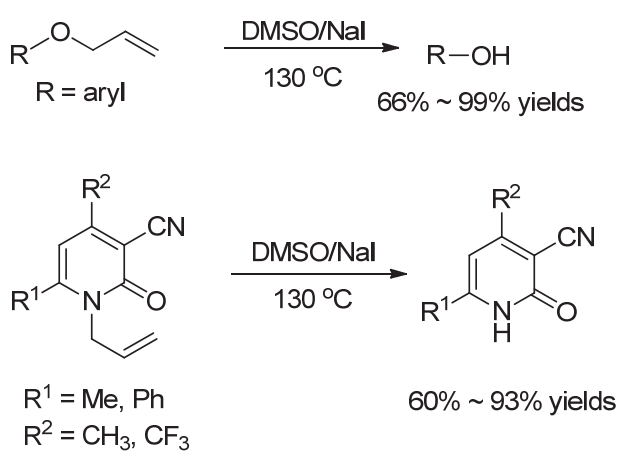

此后, Lokhande 课题组 ${ }^{[41]}$ 先后报道了使用催化量 $(10 \mathrm{~mol} \%)$ 的碘分子，以 DMSO 或聚乙二醇(PEG-400)作 为溶剂, 成功断裂碳一氧键, 实现烯丙基醚及羧酸烯丙 基酯的脱烯丙基保护，得到对应的醇(酚)和羧酸产物的 方法(Eq. 24)

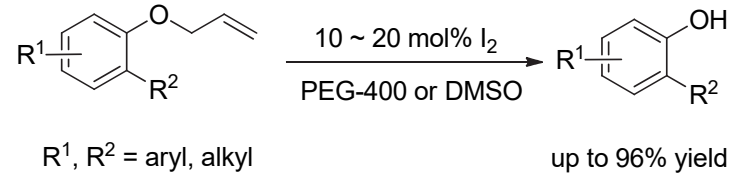

当反应底物中存在 $N$-烯丙基时，该反应体系可以 选择性地断裂碳一氧键脱去烯丙基醚的烯丙基保护而 $N$ 烯丙基不受影响. 该体系对苄基、对甲氧苄基、甲氧基、 乙酰基和氯原子均具有良好的兼容性. 作者认为当溶剂 为 DMSO 时, 被极化的碘分子会促进底物脱烯丙基保 护和去氢芳构化过程; 而使用聚乙二醇作为溶剂时，该 体系并不需要额外加入相转移催化剂或酸性催化剂, 聚 乙二醇在该反应中不仅作为溶剂，还起到了类似于 “冠 醚” 的作用: 当碘分子加入体系后，它会活化烯丙基醚 上的碳一碳双键形成一种三元碘鎓离子中间体，由于该 碘鎓离子中间体与聚乙二醇的氧原子会存在(配位型)相 互作用，其结构得以稳定(Scheme 12). 然后它接受被聚 乙二醇活化的碘阴离子的进攻，碳一氧键断裂生成相应 的脱保护产物. 体系的颜色在反应过程中保持不变，证 明了碘分子的再生过程.

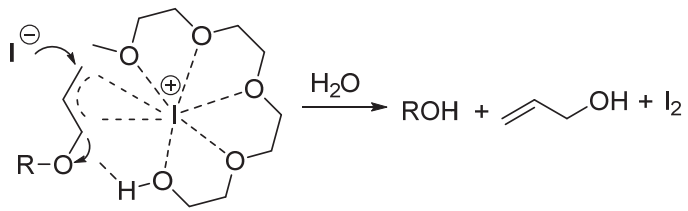

图式 12 聚乙二醇中碘促进的脱烯丙基可能的反应机理 Scheme 12 Proposed mechanism of iodine-promoted deallylation in PEG 
2017 年, Lokhande 课题组 ${ }^{[42]}$ 又报道了使用 1.1 equiv. 的碘分子对芳基烯丙基醚的脱保护方法. 使用 $\mathrm{I}_{2} /$ DMSO 脱烯丙基体系得到的是芳基烯丙基醚的先脱 烯丙基保护再碘代的产物. 当使用 1.1 equiv. 的碘分子, DMSO 作溶剂, $110{ }^{\circ} \mathrm{C}$ 条件下, 实现了芳基烯丙基醚的 脱保护，同时羟基邻位或对位被碘代(Eq. 25). 使用该体 系时, 底物中含有的甲氧基、硝基以及对酸性敏感的醛 基、酮羰基等结构单元能得以保留; 此外, 该体系还能 实现茮基烯丙酯的脱烯丙基保护得到相应的羧酸产物.

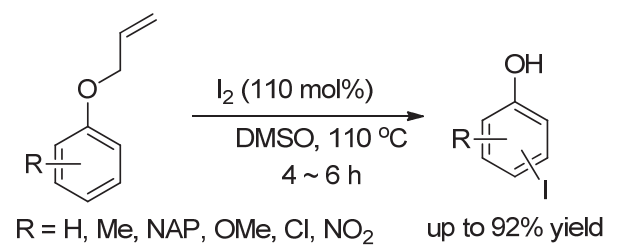

\section{5 过渡金属促进或催化的脱烯丙基反应}

近年来, 随着过渡金属促进或催化的有机化学反应 的发展，过渡金属促进或催化的脱烯丙基化反应体系相 继被报道. 烯丙基的结构特点使过渡金属可以选择性地 与其发生反应，使脱烯丙基化反应可以在温和条件下， 高效且高选择性地发生. 因此, 过渡金属化合物经过不 同的方式促进或催化碳-氧键及碳一氮键断裂来实现脱 烯丙基化的反应受到了研究者的广泛关注.

\section{1 钛促进的脱烯丙基反应}

1989 年, Chandrasekaran 课题组 ${ }^{[43]}$ 报道了低价钛(II) 物种(可由 $\mathrm{TiCl}_{4}$ 现场还原得到), 通过还原烯丙酯实现脱 烯丙基化, 得到相应的羧酸产物的体系. 该体系对卤代 芳环和烷基取代芳环有良好的兼容性. 当底物中存在苄 基保护基时，芐基也会发生脱除(Eq. 26).

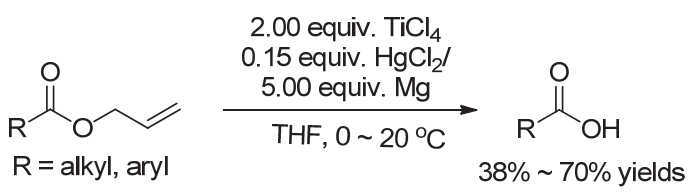

作者认为该脱烯丙基反应经低价钛(II)物种的还原 作用后会生成自由基阴离子中间体，该中间体再经碳氧键断裂形成羧酸根与一分子的稳定的烯丙基自由基 (Scheme 13).<smiles></smiles>

图式 13 低价钛(II)物种还原脱烯丙基化的反应历程 Scheme 13 Reaction pathway of reductive deallylation with Ti(II) species
1992 年, Banerji 课题组 ${ }^{[4]}$ 报道低价金属钛 $\left(\mathrm{TiCl}_{3}\right.$ Mg-THF)促进烷基醚或芳基醚脱去烯丙基或芐基保护 的方法. $\mathrm{Mg}$ 作为高价钛的还原剂时该体系脱烯丙基化 反应的活性最高(Eq. 27). 若底物中同时存在茮氧基, 该 体系能选择性地得到脱去烯丙基的产物而芐氧基不被 破坏. 作者认为该反应过程先经历活性低价钛物种对保 护基所在一侧的碳一氧键进行氧化加成, 再通过 $\mathrm{Ti}-\mathrm{O}$ 键的断裂得到相应的醇盐/酚盐阴离子. 1998 年, Banerji 课题组 ${ }^{[45]}$ 在研究醛或酮的 McMurry 偶联反应时, 发现 加入 0.25 equiv. 的 $\mathrm{I}_{2}$ 有利于提高低价钛试剂(LVT)的反 应活性. 并且除了推动 McMurry 偶联反应的发生外, 该 体系也能在较低的温度下, 以较高的反应速率应用于由 单电子转移过程引导的碳一氧键或碳一氮键断裂脱烯丙 基的过程. 作者将该低价钣试剂应用在芳香烯丙基醚、 芳香烯丙基胺、二级脂肪茮基醚和芳香芐基胺的脱烯丙 基或芳基保护中. 并针对 $\mathrm{TiCl}_{3}$ - $\mathrm{Li}-\mathrm{THF}$ 体系在有无 0.25 equiv.的 $\mathrm{I}_{2}$ 作为活化试剂的条件下对反应的时间、所需 温度及产率进行了对比, 进一步验证了 $\mathrm{I}_{2}$ 在该反应中起 到的显著活化作用. 针对反应进行的机理以及 $\mathrm{I}_{2}$ 的促进 原理，作者认为体系中的 $\mathrm{TiCl}_{3}$ 先经过还原试剂 $\mathrm{Li}$ 的还 原后, 生成零价铁物种. 然后零价铁物种可能会受相对 氧化还原电势的影响, 倾向于与体系中的 $\mathrm{I}_{2}$ 加成生成 $\mathrm{TiI}_{2}$ 物种, $\mathrm{TiI}_{2}$ 物种接着与 $\mathrm{Ti}$ 反应生成反应活性更高的 TiI 物种. 作者认为实际上推动反应进行的可能是活性 更高的 $\mathrm{TiI}_{2}-\mathrm{Ti}$ 体系, 并将其与 $\mathrm{I}_{2}$ 对 $\mathrm{Mg}$ 试剂的相似活化 作用进行了类比.

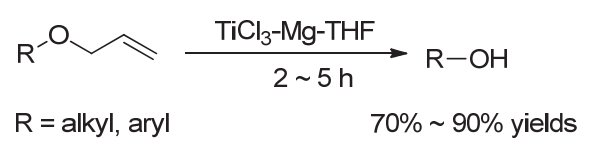

1996 年, Cha 课题组 ${ }^{[46]}$ 发展了使用 $\mathrm{Ti}(\mathrm{O}-i-\mathrm{Pr})_{4}$ 和格 氏试剂, 经历一步反应直接选择性脱去烯丙基醚的烯丙 基保护得到相应的醇的方法. 该体系能有效兼容含硅基 才三异丙基硅基(TIPS), 并且能保持底物的立体构型 (Eq. 28). 此外，该体系也适用于烯丙酯的脱烯丙基化反 应, 得到对应的羧酸产物(Eq. 29).

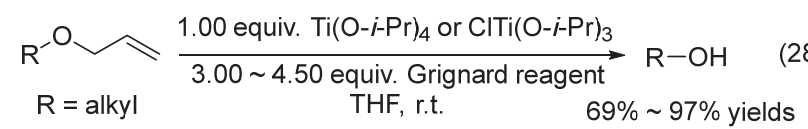

Grignard reagent $=n-\mathrm{BuMgCl}$ or cyclo- $\mathrm{C}_{6} \mathrm{H}_{11} \mathrm{MgCl}$

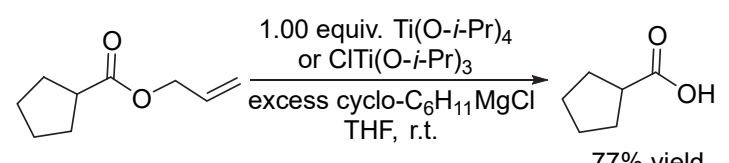


2007 年, Okamoto 课题组 ${ }^{[47]}$ 报道用 $\mathrm{Ti}(\mathrm{O}-i-\mathrm{Pr})_{4} /$ $\mathrm{TMSCl} / \mathrm{Mg}$ 体系进行脱烯丙基反应, 使用催化量的钛可 以实现芳基烯丙基醚或芳基炔丙基醚的脱烯丙基或炔 丙基保护，得到相应的酚产物(Scheme 14).

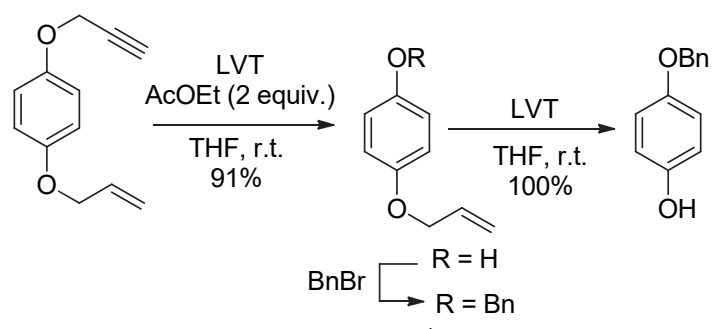

LVT (low valent Ti) : Ti(O'Pr $)_{4} / \mathrm{TMSCl} / \mathrm{Mg}$

图式 14 低价钛催化的选择性脱烯丙基化

Scheme 14 Selective deallylation catalyzed by LVT

具体反应条件为: 使用 0.05 equiv. 的 $\mathrm{Ti}(\mathrm{O}-i-\mathrm{Pr})_{4}$ 作 为催化剂, 2 equiv. 的 $\mathrm{Mg}$ 作为还原剂产生低价钛物种, 再加入 0.15 equiv. 的 $\mathrm{TMSCl}$ 或 $\mathrm{MgBr}_{2}$ 作为卤化试剂, THF 作为溶剂，室温下可高效脱去底物的烯丙基或炔丙 基保护，得到对应的醇(Eq. 30).

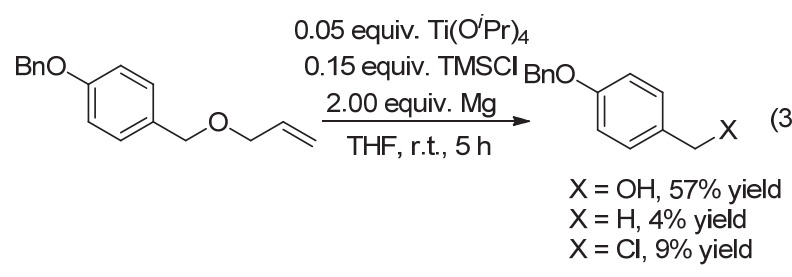

该体系对于一级脂肪烯(炔)丙基醚、二级脂肪烯 (炔)丙基醚和芳香烯(炔)丙基醚都能以较高产率得到对 应的脱保护产物, 并且对苄基、硅基、缩醛、缩酮结构 以及碳一碳双键都具有较好的兼容性. 当体系中含有不 与烯丙基相连的酯基时, 该体系催化的脱烯丙基过程会 受到阻碍而对脱炔丙基过程无影响, 作者认为这可能是 低价钛试剂中钛原子和酯羰基配位产生致钝效应的影 响. 此外, 该体系可以用于一级脂肪醇或二级脂肪醇的 碳酸烯丙酯的脱保护反应得到相应的醇.

2003 年, Rajakumar 等 ${ }^{[48]}$ 报道 $\mathrm{TiCl}_{4} / \mathrm{Zn}$ 体系在 1,4二氧六环的回流条件下也可以实现芳基烯丙基醚的脱 烯丙基反应(Eq. 31). 文章中提出二氧六环可在体系中 充当亲核试剂, 推动 $\mathrm{O}-\mathrm{TiCl}_{3}$ 中间体络合物中 $\mathrm{Ti}-\mathrm{O}$ 键 的断裂.

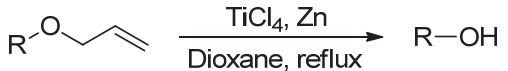

$$
\begin{aligned}
& \mathrm{R}=\mathrm{C}_{6} \mathrm{H}_{5}, o-, m-, p-\mathrm{CH}_{3} \mathrm{C}_{6} \mathrm{H}_{4} \quad 80 \% \sim 90 \% \text { yields }
\end{aligned}
$$

\section{2 锆促进的脱烯丙基反应}

1993 年, Hanzawa 课题组 ${ }^{[49]}$ 报道了 1.3 equiv. 的二茂
锆(由正丁基锂和二氯二茂锆现场制备生成), 在 THF 作 溶剂的条件下，低温下实现烯丙基醚或烯丙基胺脱烯丙 基保护的方法(Eqs. 32, 33).

$$
\begin{aligned}
& \curvearrowright_{\mathrm{OR}} \frac{1.3 \text { equiv. } \mathrm{Cp}_{2} \mathrm{Zr}}{\mathrm{H}_{3} \mathrm{O}^{+}} \mathrm{R}-\mathrm{OH} \\
& \mathrm{R}=\text { alkyl } \quad 50 \% \sim 98 \% \text { yields }
\end{aligned}
$$

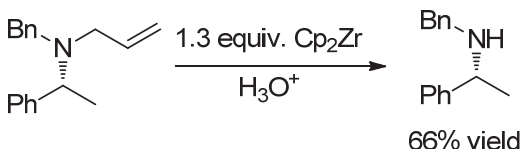

当烯丙基醚和烯丙基胺等量共存时，使用 1 equiv. 的二茂锆，该体系能选择性地断裂碳一氧键，脱去烯丙 基醚的烯丙基保护而烯丙基胺不被破坏(Eqs. 34，35). 同时该脱保护体系对较为敏感的其他保护基(如四氢吡 喃、缩醛等)呈现良好的兼容性，其中三取代烯烃的双键 能在脱保护过程中得以保留, 该体系不会改变底物分子 原有的立体构型. 此外，当底物分子中有酯基存在时， 该体系的脱烯丙基产率会大大降低，可能是由于使用 1.3 equiv.的二茂锆会进攻酯㷇基，导致酯基的水解.

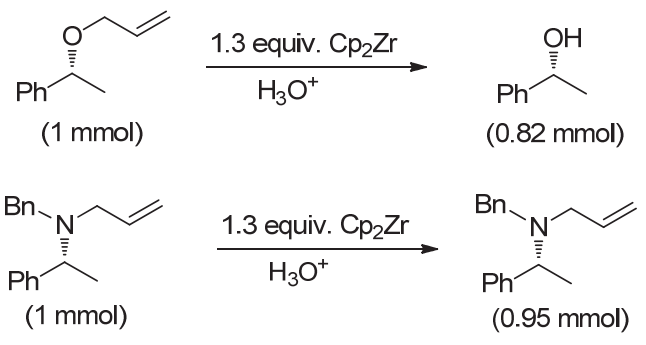

\section{3 铑催化脱烯丙基反应}

1973 年, Corey 等[50]报道 Wilkinson 催化剂 $\left(\mathrm{Ph}_{3} \mathrm{P}\right)_{3} \mathrm{RhCl}$ 催化的烷基烯丙基醚脱烯丙基的方法. $\left(\mathrm{Ph}_{3} \mathrm{P}\right)_{3} \mathrm{RhCl}$ 为催化剂, 加入催化量 1,4-二氮杂二环 [2.2.2]辛烷(DABCO)在乙醇回流条件下，烯烃发生异构 化反应形成烯醇醚，然后其在酸性条件水解实现脱烯丙 基反应得到相应的醇(Scheme 15). 该反应体系对烷基 醚、芳基醚、酯及茮醚具有很好的兼容性. 随后 Gigg 等 ${ }^{[51]}$ 研究了不同烯丙基醚类化合物在 $\left(\mathrm{Ph}_{3} \mathrm{P}\right)_{3} \mathrm{RhCl}$ 催化 下的异构化及使用 ${ }^{t} \mathrm{BuOK}$ 在 DMSO 溶剂中异构化为烯 醇醚的速度差异. 不同烯丙基醚在 $\left(\mathrm{Ph}_{3} \mathrm{P}\right)_{3} \mathrm{RhCl}$ 催化下 的异构化速度顺序为：烯丙基 $>2$-甲基烯丙基 $>2$-丁烯 基 $\gg 2$-甲基-2-丁烯基; 使用 ${ }^{t} \mathrm{BuOK}$ 在 DMSO 溶剂中异

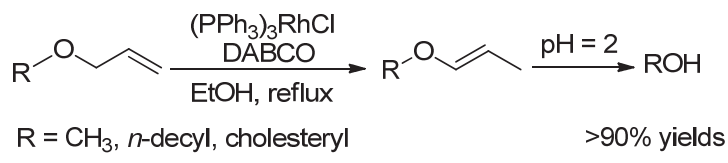

图式 15 铑催化的异构化脱烯丙基反应

Scheme 15 Rh-catalyzed deallylation via isomerization 
构化速度为顺序为 2-甲基-2-丁烯基，2-丁烯基 $>$ 烯丙 基 $>2$-甲基烯丙基.

铑催化的脱烯丙基化反应通常经历异构化过程得 到烯醇醚, 然后烯醇醚再进行水解或氧化得到相应的脱 烯丙基产物. 然而在烯醇醚的水解或氧化过程中可能发 生的副反应导致脱烯丙基化的产率降低或产物难以纯 化. 1988 年, Sundberg 等 ${ }^{[52]}$ 报道铑催化的烯丙基叔胺一 步脱烯丙基的方法. 该方法使用 $25 \mathrm{~mol} \%$ 的 $\left(\mathrm{Ph}_{3} \mathrm{P}\right)_{4} \mathrm{RhH}$ 为催化剂, 在等物质的量的三氟乙酸存在下, 乙醇回流 条件下可以实现烯丙基胺的脱烯丙基反应(Eq. 36). 1990 年, Ziegler 等 ${ }^{[33]}$ 将这一铑催化的脱烯丙基方法用于烯丙 基醚类化合物的脱烯丙基反应, 使用 $3 \mathrm{~mol} \%$ 的催化剂 就可以实现烯丙基醚的脱烯丙基反应. 不同结构的烯丙 基醚的反应活性为烯丙基 $>$ 单甲基取代的烯丙基 $>$ 二 甲基取代的烯丙基.

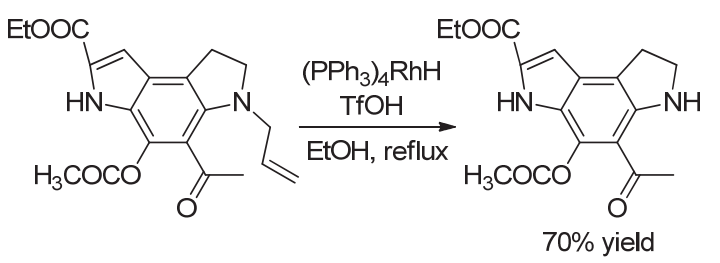

2007 年, Zacuto 等 ${ }^{[54]}$ 报道了一种无需配体修饰的铑 催化一步法脱去酰胺氮原子上烯丙基保护的方法. 以氯 化铑为催化剂, 回流的异丙醇条件下可一步实现 $N$-烯 丙基酰胺脱烯丙基(Eq. 37). 反应历程为铑催化烯烃异 构化后, 在较高的温度下, 由 $\mathrm{RhCl}_{3}$ 原位生成的 $\mathrm{HCl}$ 催 化烯酰胺中间体转化为仲酰胺. 这一反应条件对含有较 大位阻和不同电负性的非环酰胺都有很高的反应活性, 对硝基、溴和缩醛等官能团有很好的兼容性.

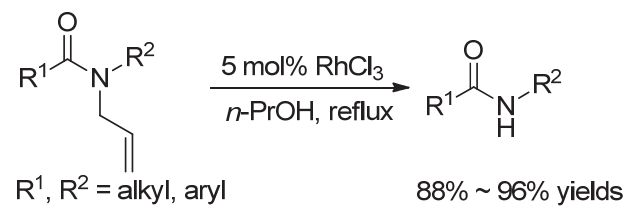

\section{4 钯催化脱烯丙基反应}

$\mathrm{Pd}$ 催化剂催化脱烯丙基保护, 由于反应条件比较 温和, 底物适用性及官能团兼容性较好, 是目前研究最 广泛的过渡金属催化的脱烯丙基方法. 目前报道的方法 主要经过两种历程: 钯催化烯丙基醚异构化为烯醇醚来 实现脱保护; 零价钯与反应底物发生氧化加成反应形成 $\eta^{3}$-烯丙基钯络合物, 随后与亲核试剂作用得到相应的 脱保护产物.

\subsection{1 钯催化经烯烃异构化历程的脱烯丙基方法}

1976 年, Scheffoid 等 ${ }^{[55]}$ 报道在催化量的 $\mathrm{Pd} / \mathrm{C}$ 及对 甲苯磺酸或高氯酸存在下, 甲醇和水为溶剂, 加热 $60 \sim$
$80{ }^{\circ} \mathrm{C}$ 可以实现烯丙基醚的脱烯丙基化(Eq. 38). 当芐基 醚和烯丙基醚的结构单元同时存在时，该催化体系可以 选择性脱除烯丙基，对于一些对酸性敏感的底物，可以 在室温条件下，通过延长反应时间来实现脱烯丙基，但 反应时间较长，例如氰基环氧丙基烯丙基醚的脱烯丙基 反应需 $6 \mathrm{~d}$. 该脱烯丙基反应通过烯烃异构化形成烯醇 醚来实现.

$$
\text { R= Ph, } n \text { - } \mathrm{C}_{8} \mathrm{H}_{17} \text {, glyceryl, NAP } \quad \frac{\begin{array}{c}
\mathrm{Pd} / \mathrm{C}, \mathrm{H}_{2} \mathrm{O}, \mathrm{MeOH} \\
\text { cat. } \mathrm{TsOH} \text { or } \mathrm{HClO}_{4}
\end{array}}{60 \sim 80^{\circ} \mathrm{C}, 24 \mathrm{~h}} \mathrm{R}-\mathrm{OH} \sim 95 \% \text { yields }
$$

1976 年, Mori 等 ${ }^{[56]}$ 报道了烯丙基胺类化合物在 1.2 equiv. 氯化钯及醋酸存在下的脱烯丙基化反应. 当反应 体系中加入等物质的量的 $\mathrm{Cu}(\mathrm{OAc})_{2}$ 或 $\mathrm{AcONa}$ 时, 可以 使用催化量的 $\mathrm{PdCl}_{2}$ 进行. 以弱酸性的醋酸作为溶剂, $60{ }^{\circ} \mathrm{C}$ 反应, 可以快速发生 $N$-烯丙基断裂, 生成脱保护产 物( $59 \% \sim 76 \%$ ), 当体系中再加入等物质的量的 $\mathrm{LiCl}$ 作 为额外氯源时，可以明显地提高反应产率(Eq. 39). 底物 中的苄基、羰基和酯基等基团在该过程当中可以保留. 该方法可以用于合成伯胺的 $N$-芳基衍生物.

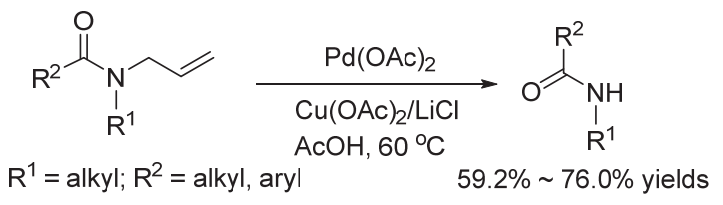

1985 年, $\mathrm{Bieg}$ 等 ${ }^{[57]}$ 报道以反式 $\mathrm{Pd}\left(\mathrm{NH}_{3}\right)_{2} \mathrm{Cl}_{2}$ 为催化 剂, 在叔丁醇溶剂中加热回流可实现糖类化合物的脱烯 丙基反应. 1992 年, Kusama 课题组 ${ }^{[58]}$ 也报道了糖类化合 物的烯丙基醚结构单元的脱烯丙基方法. 使用 $\mathrm{Pd}\left(\mathrm{PPh}_{3}\right)_{4}$ 作为催化剂, $80{ }^{\circ} \mathrm{C}$ 条件下, 在醋酸溶液中反 应 $1 \mathrm{~h}$ 左右就能得到 72\% 98\%的收率(Eq. 40). 该体系 对糖苷类化合物异头碳上的 $O$-烯丙基的脱除具有很好 的选择性，同时不会干扰其他位置上羟基的保护基.

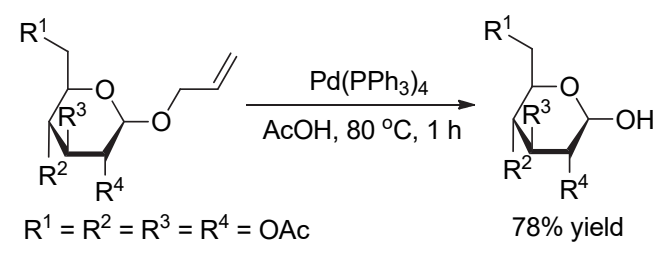

1993 年, Mereyala 等 ${ }^{[59]}$ 也报道了一种糖苷和肌醇类 化合物选择性脱除异头碳上的 $O$-烯丙基保护基的方法. 使用等物质的量的 $\mathrm{Pd}(\mathrm{II})$ 作为催化剂, $\mathrm{Cu}(\mathrm{I})$ 作为助催化 剂, $\mathrm{DMF} / \mathrm{H}_{2} \mathrm{O}(V: V=10: 1)$ 作为溶剂, 室温下反应 1 $6 \mathrm{~h}$ ，可以以 $90 \% \sim 92 \%$ 的产率得到相应的脱烯丙基产物 (Eq. 41). 对于烯醇醚在催化量的 $\mathrm{Pd}(\mathrm{II})$ 存在下, 反应 
10 15 min, 即可以 $88 \% \sim 92 \%$ 的收率得到产物, 由此 推测反应可能经历了烯烃异构化的中间体的过程.

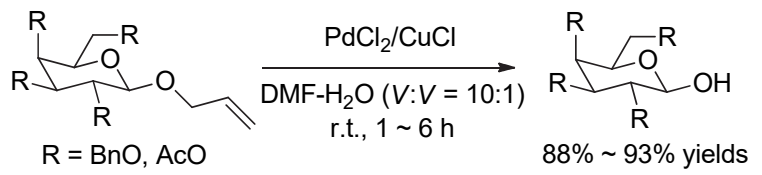

1997 年, Nagakura 等 ${ }^{[60]}$ 使用亚磺酸或其相应的盐在 催化量的 $\mathrm{Pd}\left(\mathrm{PPh}_{3}\right)_{4}$ 催化下, 高效地实现了各类取代的 烯丙基碳酸酯、烯丙基醚以及烯丙基胺的脱烯丙基反应 (Eq. 42). 由于反应条件温和, 该方法适用于大环内酯、 核苷酸、糖类化合物以及生物碱等复杂天然产物的脱烯 丙基化反应。

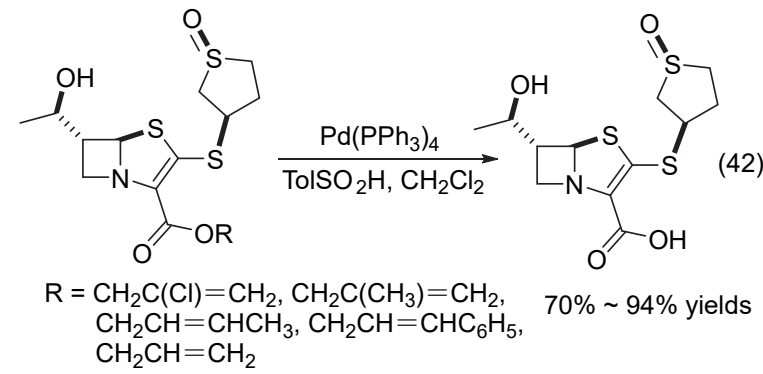

Ishizaki 和 Hara 等[61]报道使用 $10 \% \mathrm{Pd} / \mathrm{C}$ 催化, 以 $\mathrm{KOH}$ 的甲醇为溶剂, 可以在室温条件下实现芳基烯丙 基醚的脱烯丙基化反应(Eq. 43). 在这个催化体系中烯 丙基醚的电性对其反应活性具有一定的影响：当底物中 具有吸电子基或弱给电子基时脱烯丙基反应可以顺利 进行，当底物中具有强给电子基时这个反应以中等或低 的产率得到相应脱烯丙基产物, 此外这个催化体系可以 用于二酚的二烯丙基醚的选择性脱一个烯丙基保护基.

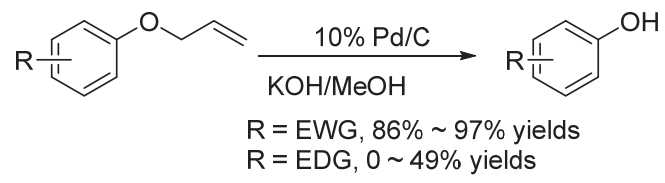

5.4 .2 钯催化经过 $\eta^{3}$-烯丙基钯络合物实现脱烯丙基 方法

作为有机合成中重要的合成方法, 钯催化的 TsujiTrost 反应(烯丙基化反应)的发展, 为脱烯丙基保护提供 了一种具有一定通用性的方法, 也促使用烯丙基进行含 氧或氮等原子的官能团保护应用增加. 根据 Tsuji-Trost 反应, 钯催化的脱烯丙基化可以通过零价钯对反应底物 进行氧化加成形成烯丙基钯物种, 然后在各种亲核试剂 的作用下实现脱烯丙基化. 亲核试剂可以为含有氧、氮 及碳的亲核试剂及一些氢给体(例如甲酸、三丁基锡氢 化合物等).

在 20 世纪 70 年代初, Hata 等 ${ }^{[62]}$ 报道了烯丙基醚及
羧酸烯丙基酯在钯催化剂存在下可以发生碳-氧键断裂. 烯丙基与反应体系内的具有氢供体的试剂(羧酸、胺等) 发生质子交换, 形成新的羧酸烯丙基酯或烯丙基胺等, 同时生成相应的醇或羧酸.

1982 年, McCombie 课题组 ${ }^{[63]}$ 报道了 $\mathrm{Pd}\left(\mathrm{PPh}_{3}\right)_{4}$ 催化 的烯丙基碳酸酯的脱除烯丙基的方法，使用 2-乙基己酸 钾作为碱, 加入催化量的 $\mathrm{PPh}_{3}$, 可以在室温下实现氨基 甲酸烯丙酯类化合物的脱保护(Eq. 44). 该方法对敏感 的底物，如具有其他保护基团、碳一碳双键等官能团的底 物兼容, 因此氨基碳酸烯丙酯发展为胺类化合物的重要 保护基团, 尤其是伯胺及氨基酸中的氨基保护基团.
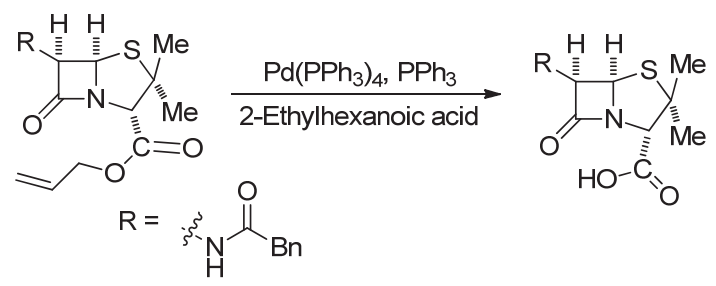

1984 年, Kunz 课题组 ${ }^{[64]}$ 报道了使用催化量的 $\operatorname{Pd}\left(\mathrm{PPh}_{3}\right)_{4}$ ，以 5,5-二甲基-1,3-环己二酮作为亲核试剂, 选择性脱烯丙基保护基的方法. 在 THF 溶液中, 室温反 应 $30 \mathrm{~min}$, 可以快速地脱除氨基酸氮原子上的碳酸烯丙 酯保护基(Eq. 45)，该方法被成功用于多肽链合成. 1985 年, Tsuji 等 ${ }^{[65]}$ 报道了氨基碳酸类化合物的烯丙基保护基 在四(三苯基膦)钯作为催化剂，甲酸存在下，30 ${ }^{\circ} \mathrm{C}$ 反应 可以实现脱保护基得到相应的胺类或氨基酸类化合物.

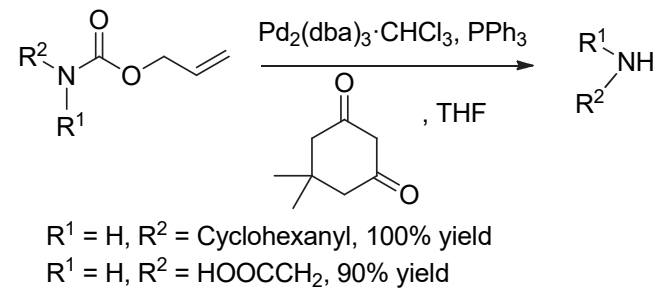

Guibé 等[66]先后报道以 $\mathrm{Pd}\left(\mathrm{PPh}_{3}\right)_{4}$ 为催化剂, 使用三 丁基锡氢、 $\mathrm{PhSiH}_{3}$ 及硅化胺类为亲核试剂来实现氨基碳 酸烯丙酯的脱保护(Eq. 46). 这些体系对氮上的 Boc 和 Fmoc 等其他保护基有很好的兼容性，可应用于多肽链 的合成. 1995 年, Roos 等 ${ }^{[67]}$ 在 Guibé 的反应体系中用酸 酐、酰氯或者活泼的酯代替醋酸, 实现了氨基碳酸烯丙 酯的脱保护. 以氮原子上带有一个保护基的 $\alpha$-氨基酯衍 生物来代替醋酸, 可以在温和条件下以较高产率实现肽 类化合物的脱烯丙基化(50\% 99\%).

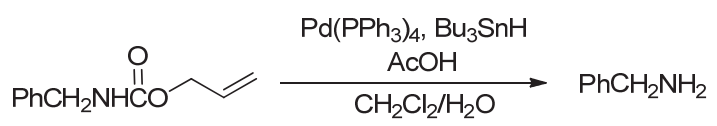


1987 年, Deziel ${ }^{[68]}$ 报道了使用四(三苯基膦)钯为催 化剂, 在吡咯烷等亲核性胺类化合物的存在下, $0{ }^{\circ} \mathrm{C}$ 反 应，可以实现烯丙酯的脱烯丙基保护，反应可以在 10 $15 \mathrm{~min}$ 内以 $66 \% \sim 93 \%$ 的收率完成(Eq. 47). 该方法可以 用于青霉素 $\mathrm{G}$ 合成中的脱保护，在酸化之后以 $93 \%$ 的分 离收率得到产物, 而且对乙酰氧等官能团具有很好的兼 容性.

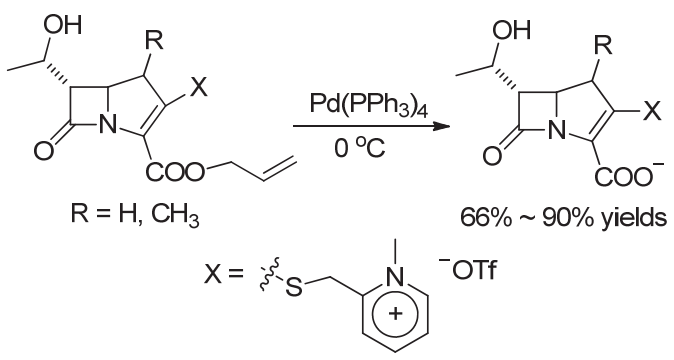

同年, Tsuji 课题组 ${ }^{[69]}$ 报道了烯丙基保护的肟类结构 的脱保护方法, 使用 $\mathrm{Pd}(\mathrm{OAc})_{2}$ 作为催化剂, $\mathrm{PPh}_{3}$ 作为配 体, 甲酸铵作为氢供体, 可以在温和条件下实现肜羟基 的脱烯丙基反应(Eq. 48). 对溶剂的篎选和底物适应性 的探究发现, 该反应在水溶性的醇和乙腈中具有最佳收 率( $>94 \%$ ), 并且对烷基醚、酯基和碳-碳双键等官能团 具有很好的兼容性.

$$
\begin{aligned}
& \underset{\mathrm{R}^{2}}{=} \sum_{\substack{\mathrm{R} 1 \\
\text { alcohol or } \mathrm{CH}_{3} \mathrm{CN}}}^{\stackrel{\mathrm{Pd}(\mathrm{OAc})_{2}, \mathrm{PPh}_{3}}{\mathrm{HCOONHEt}_{3}}} \underset{\mathrm{R}^{2}}{\mathrm{R}^{1}}=\mathrm{N}-\mathrm{OH}+\curvearrowright \\
& \mathrm{R}^{1}=\text { alkyl, aryl; } \mathrm{R}^{2}=\text { alkyl }
\end{aligned}
$$

1993 年, Guibé 等[70]报道在 $\mathrm{Pd}\left(\mathrm{PPh}_{3}\right)_{4}$ 的催化下, 使 用 $N, N$-二甲基巴比妥酸作为亲核试剂, $30{ }^{\circ} \mathrm{C}$ 反应 $1 \sim 3$ $\mathrm{h}$ 可以实现烯丙基胺及胺的烯丙基碳酸酯的脱保护, 得 到产物为对应的胺的盐酸盐 $(91 \% \sim 100 \%)(\mathrm{Eq}$. 49). 在 该反应条件下，对同时含有烯丙氧羰基和烯丙基保护的 胺，会优先脱除烯丙氧羰基.

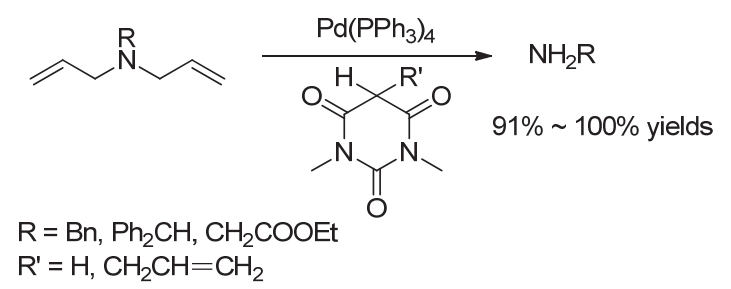

作者对反应的机理进行了探讨, 烯丙基胺首先接收 巴比妥酸上的质子生成铵盐, 然后铵盐在 $\operatorname{Pd}(0)$ 的催化 下脱去烯丙基生成烷基胺，同时生成 Pd-烯丙基中间体, 该中间体通过和巴比妥酸负离子反应回到 $\operatorname{Pd}(0)$, 完成 催化循环(Scheme 16).

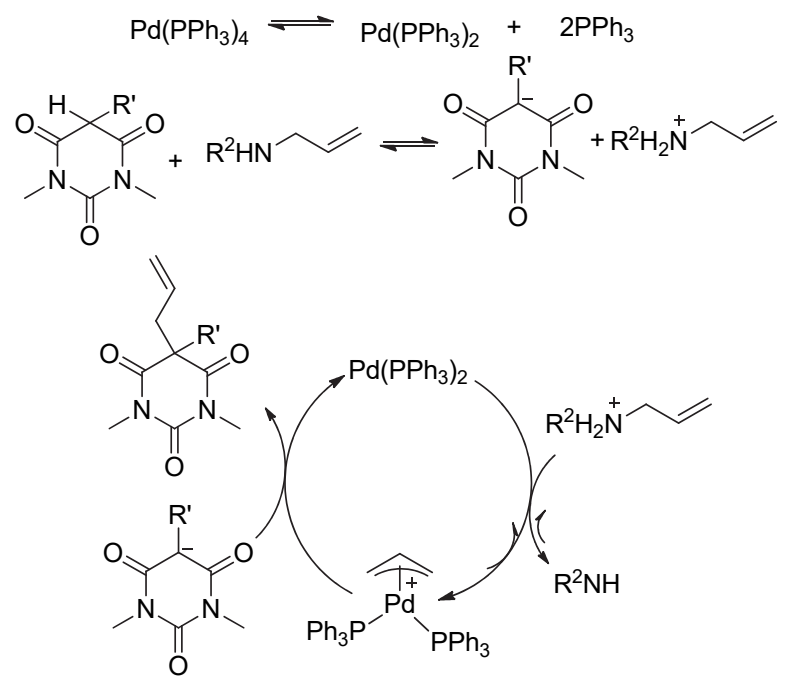

图式 $16 \mathrm{Pd}(\mathrm{PPh})_{4}$ 催化胺类化合物脱除烯丙基保护基机理 Scheme 16 Mechanism of $\mathrm{Pd}(\mathrm{PPh})_{4}$ catalyzed deallylation of amines

1994 年, 祝介平等[71]报道使用四(三苯基膦)钯作为 催化剂, 在室温条件下, 使用 1.5 equiv. 的 $\mathrm{NaBH}_{4}$ 可以实 现芳基烯丙基醚和芳基烯丙基酯的脱烯丙基反应(Eq. 50). 该方法可以兼容容易被还原的硝基、䍨酸、酰胺、 氰基、碳酰胺以及酰亚胺，对于手性原料在脱保护过程 中可以保持其立体构型.

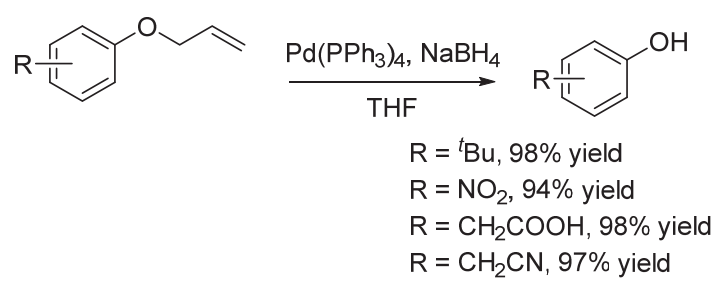

在钯催化的脱烯丙基化反应的研究中，除了使用不 同的亲核试剂，对催化体系配体的调控也可改变催化体 系的反应活性及选择性. Genêt 等 ${ }^{[72]}$ 先后使用 $\mathrm{Pd}(\mathrm{dba})_{2} /$ 1,4-双 (二苯基膦)丁烷(DPPB)为催化剂, 以 2-颈基苯甲 酸或二乙胺作为亲核试剂, 有效实现了二级和三级烯丙 基胺的脱烯丙基反应(Eq. 51), 对于二烯丙基保护的伯 胺可以通过调节反应条件实现分步脱烯丙基化.

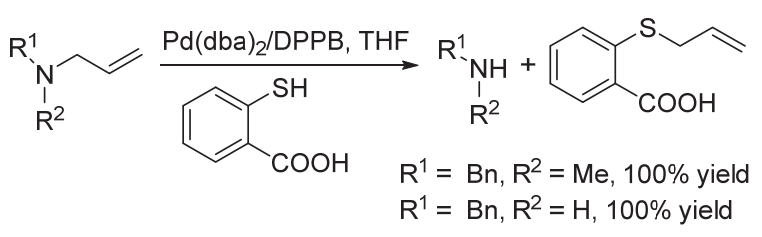

Genêt 等 ${ }^{[73]}$ 报道了使用 $\operatorname{Pd}(\mathrm{OAc})_{2}$ 作为催化剂，以三 苯基膦三间磺酸钠盐(TPPTS)为配体，以二乙胺作为亲 核试剂, 可以实现烯丙酯和一级/二级氨基碳酸烯丙酯 
的脱保护。通过调节反应溶剂，可以对具有不同空间位 阻的烯丙酯进行选择性的脱烯丙基反应. 当反应溶剂为 丁腈-水组成的非均相体系时，该催化体系可以选择性 地脱除位阻小的烯丙酯基; 当反应溶剂为乙腈-水体系 时, 可以进一步实现脱除大位阻的烯丙酯基 (Scheme 17). 该反应条件温和可以兼容比较敏感的官能团, 适 用于氨基酸的多肽链的组装.

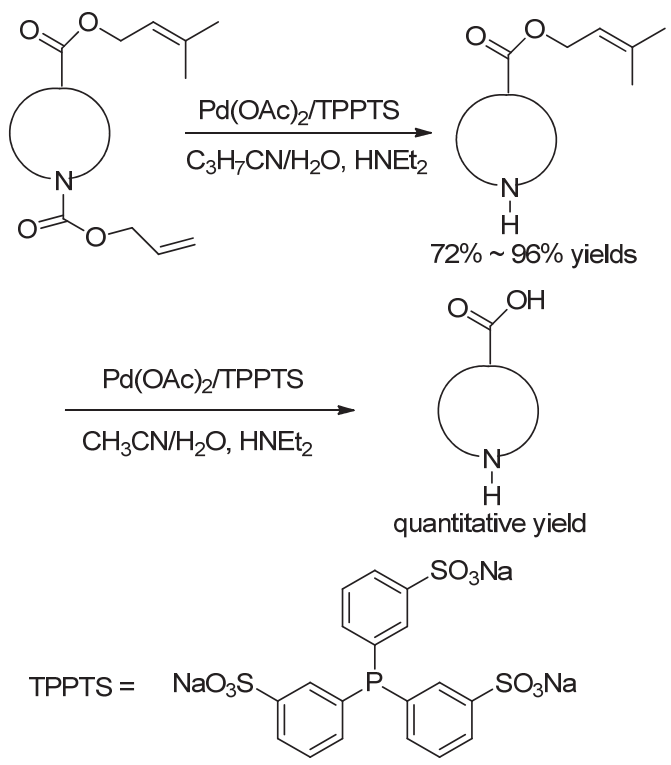

图式 $17 \mathrm{Pd}(\mathrm{OAc})_{2} / \mathrm{TPPTS}$ 催化的选择性脱烯丙基化 Scheme 17 Selective deallylation catalyzed by $\mathrm{Pd}(\mathrm{OAc})_{2} /$ TPPTS

1995 年, Kondo 等 ${ }^{[74]}$ 报道了使用 $\mathrm{Pd}(\mathrm{OAc})_{2}$ 及 $\mathrm{P}(\mathrm{OEt})_{3}$ 的催化体系, 在 $\mathrm{THF} / \mathrm{H}_{2} \mathrm{O}(V: V=3: 1)$ 的溶液 中, 可以选择性地脱除碳青霉烯类化合物的烯丙基保护 (Eq. 52).

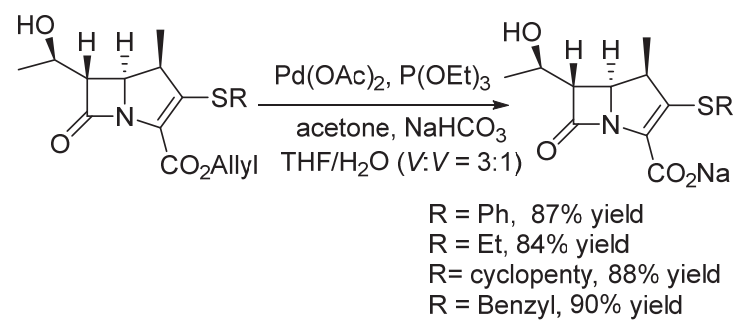

2004 年, Murakami 等 ${ }^{[75]}$ 报道使用 1,2-双(4-甲氧基 苯基)-3,4-双(2,4,6-三叔丁基苯基次膦基)环丁烯(DPCB$\mathrm{OMe}$ )配位的烯丙基钯络合物([ $\left.\mathrm{Pd}\left(\eta^{3}-\mathrm{C}_{3} \mathrm{H}_{5}\right)(\mathrm{DPCBOMe})\right]-$ OTf), 以苯胺作为亲核试剂可以高效地催化烯丙基醚及 烯丙基酯的脱烯丙基反应(Eq. 53). 该反应体系对芳基 烯丙基醚、烷基烯丙基醚及烯丙酯的脱烯丙基都具有很 好的反应效果, 对其他的保护基团如叔丁基二甲基硅基 (TBDMS)、THP 和甲氧基甲基(MOM)等具有很好的兼
容性. 在脱烯丙基反应中通常烯丙基酯的反应活性高于 烯丙基醚类化合物，对于 2-烯丙氧基苯甲酸烯丙酯，在 该催化体系下可以选择性地实现烯丙基醚结构中烯丙 基的优先脱除，得到等物质的量的水杨酸烯丙酯.

$$
\text { R- } \mathrm{R}-\mathrm{OH}
$$

2008 年, Floch 等 ${ }^{[76]}$ 报道膦杂茂烯丙基钯阳离子络 合物与苯胺及催化量的 $\mathrm{NH}_{4} \mathrm{PF}_{6}$ 的反应体系可以有效地 实现芳基及烷基烯丙基醚的脱烯丙基化反应(Eq. 54), 并通过密度泛函理论(DFT)计算证明酸性催化剂 $\mathrm{NH}_{4} \mathrm{PF}_{6}$ 在促进烯丙基醚的碳一氧键断裂中具有重要的作用.

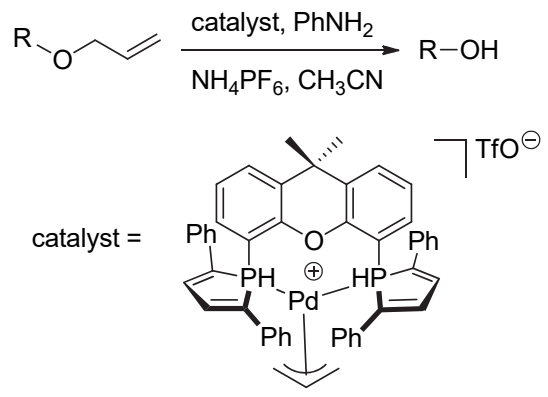

廉价的 $\mathrm{NaH}$ 是化学转化中最常用的试剂之一, 其 在有机合成中通常作为碱使用，很少被用作还原剂或亲 核试剂. 2018 年, 王为课题组 ${ }^{[77]}$ 报道以 $N, N$-二甲基乙酰 胺(DMA)为溶剂时, $\mathrm{NaH}$ 可以作为亲核试剂应用在钯催 化的脱烯丙基化反应中. 以 $\operatorname{Pd}(\mathrm{OAc})_{2}$ 为催化剂, 使用 1.5 equiv. 的 $\mathrm{NaH}$ 作为亲核试剂可以实现芳基烯丙基醚 (Eq. 55)及烯丙基酯(Eq. 56)的脱烯丙基化反应，该催化 体系对芳基烯丙基醚显示高的反应选择性，具有广泛的 官能团兼容性.

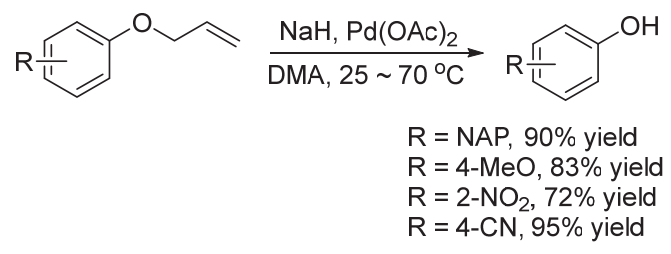




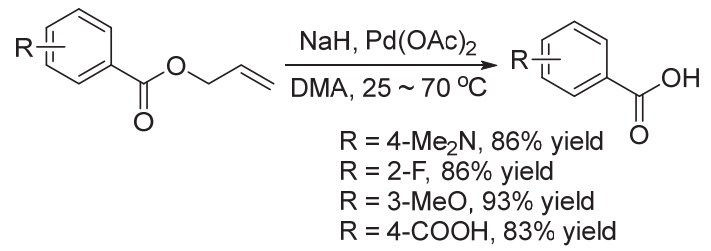

2010 年, Marques 等[78]在氨基糖苷类化合物的官能 团化过程当中, 以四(三苯基膦)钯为催化剂, 使用三乙 基硅烷(TES)为还原剂, 室温下反应 $24 \mathrm{~h}$, 再加入单质碘 以 $48 \% \sim 51 \%$ 的产率得到脱烯丙基保护的产物(Scheme 18).
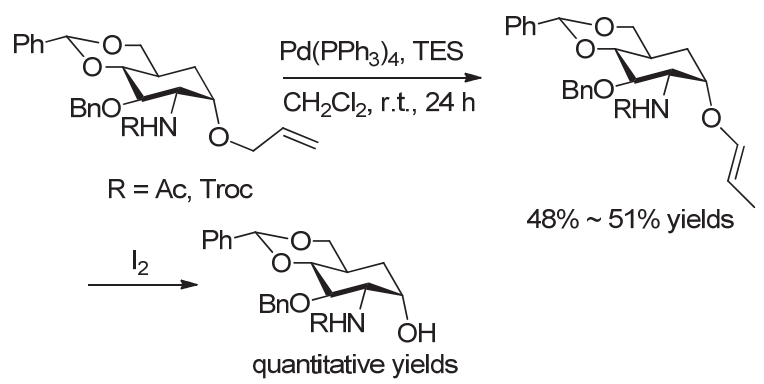

图式 $18 \mathrm{Pd}\left(\mathrm{PPh}_{3}\right)_{4} / \mathrm{TES}$ 催化糖苷类化合物脱烯丙基化反应 Scheme 18 Deallylation of glycosides catalyzed by $\mathrm{Pd}\left(\mathrm{PPh}_{3}\right)_{4} /$ TES

2015 年, Takagi 等 ${ }^{[3 b]}$ 报道了非均相钯催化的烯丙基 酯脱烯丙基保护的方法. 将用硫处理过的金和醋酸钯在 二甲苯溶液中混合制得的不易然的纳米 Pd 作为催化剂, 不加配体, 在过量的甲酸和三乙胺存在下, 乙腈溶液中 $80{ }^{\circ} \mathrm{C}$ 反应 $1 \mathrm{~h}$, 可以以大于 $90 \%$ 的产率得到相应的脱烯 丙基产物, 并且钯催化剂几乎完全回收(Eq. 57).

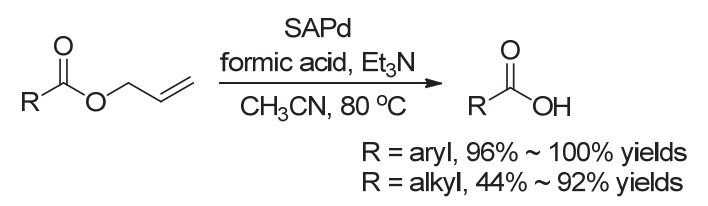

钯催化脱烯丙基化反应经过多年的研究和发展, 其 催化效率较高, 可以在比较温和的条件下实现, 且具有 较好的底物适用性. 这类脱烯丙基化反应不仅可用于药 物分子及复杂天然产物的合成, 也被应用于研究药物分 子及材料等中残留钯的检测 [3a,3c] 以及生物检测 中 [79]. Koide 等 ${ }^{[80]}$ 首先将钯催化的脱烯丙基化反应应用到苂光 检测药物及材料中残余的钯. 将具有苂光性的化合物进 行烯丙基保护后得到非苂光化合物作为指示剂, 将预处 理过的药物或材料溶于 DMSO 及 $\mathrm{pH}$ 为 7 的缓冲溶液, 向体系中加入指示剂、三(2-呋喃)膦(TEP)和嗍氢化钠, 检测物中残留钯可以作为催化剂脱去指示剂的烯丙基 得到有苂光的产物, 根据苂光的强度, 定量地检测体系 中残留的 Pd 的含量(Eq. 58), 检测限可到 $1 \mu \mathrm{mol} / \mathrm{L} .2017$
年, 该课题组用肼代替嗍氢化钠作为还原试剂, 弥补了 原来检测体系中嗍氢化钠难以保存且对 $\mathrm{Pt}$ 也有一定响 应的缺点 ${ }^{[81]}$.

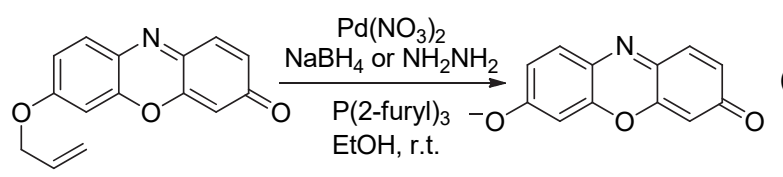

2018 年, Brik 课题组 ${ }^{[82]}$ 报道使用谷氨酸作为钯催化 脱烯丙基化的亲核试剂，使脱烯丙基反应可以在水相中 进行，该体系可以应用于多肽化合物的合成. 作者将天 冬氨酸或谷氨酸的侧链着基用烯丙基保护，与半胱氨酸 反应，然后在完全水性的条件下，使用 $[\mathrm{Pd}(\operatorname{allyl}) \mathrm{Cl}]_{2}$ 和 谷胱甘肽反应，可以快速脱去羧酸上的烯丙基保护来实 现快速、高选择性的多肽合成(Scheme 19).
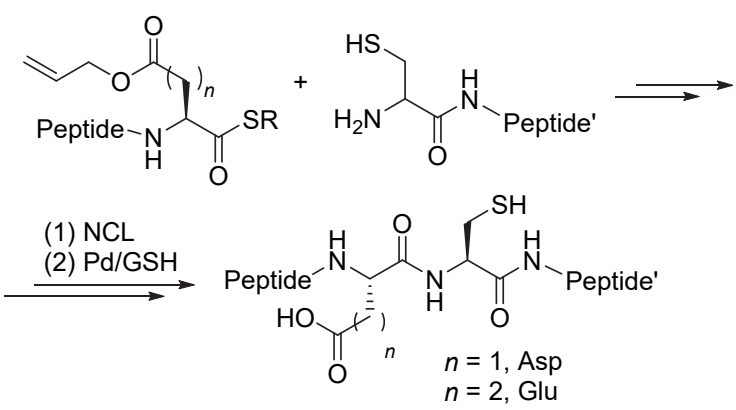

图式 $19[\mathrm{Pd}(\mathrm{allyl}) \mathrm{Cl}]_{2} / \mathrm{GSH}$ 催化氨基酸中羧基的脱烯丙基化 反应

Scheme 19 Deallylation of carboxyl groups of amino acids catalyzed by $[\mathrm{Pd}(\text { allyl }) \mathrm{Cl}]_{2} / \mathrm{GSH}$

2018 年, Martínez-Calvo 等[79]设计了一类膦配体, 使 $\mathrm{Pd}$ 催化的脱烯丙基反应可以在细胞液中进行(Eq. 59). 这类配体的疏水性鏻盐的设计，使其与钯形成的 催化剂在哺乳动物的活细胞中具有良好的反应性和稳 定性, 且在线粒体中表现出优先积累. 这类亚细胞靶向

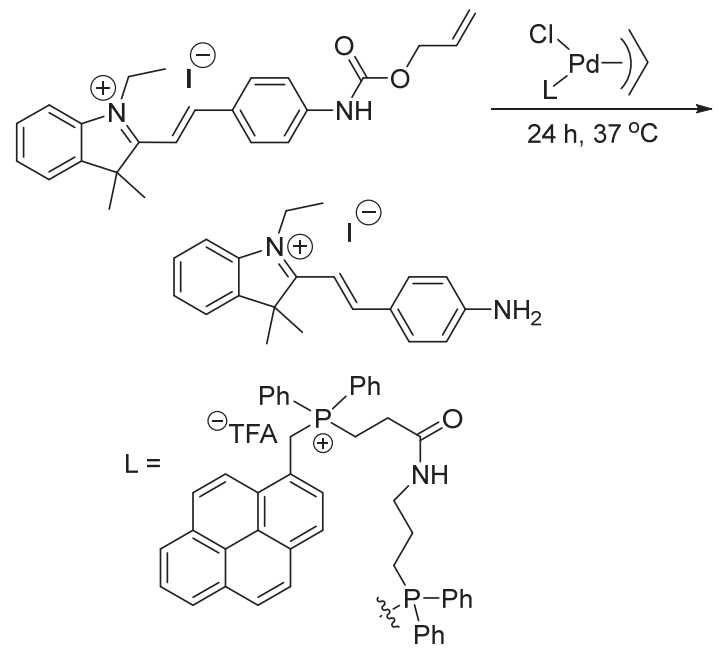


反应催化剂可能为药物的释放提供新的途径.

\section{6 钉催化脱烯丙基反应}

在过渡金属催化的脱烯丙基化反应中当中，钉金属 催化剂同样得到了详细的研究. 1990 年, Nicolaou 等 ${ }^{[8]}$ 将 $\mathrm{H}_{2} \mathrm{Ru}\left(\mathrm{PPh}_{3}\right)_{4}$ 催化的脱烯丙基反应应用于鞘糖脂的合 成中. $\mathrm{H}_{2} \mathrm{Ru}\left(\mathrm{PPh}_{3}\right)_{4}$ 催化烯丙基保护的糖类化合物在乙醇 回流条件下发生异构化得到相应的烯醇醚, 然后在对甲 苯磺酸催化下水解得到脱烯丙基保护的产物(Eq. 60).

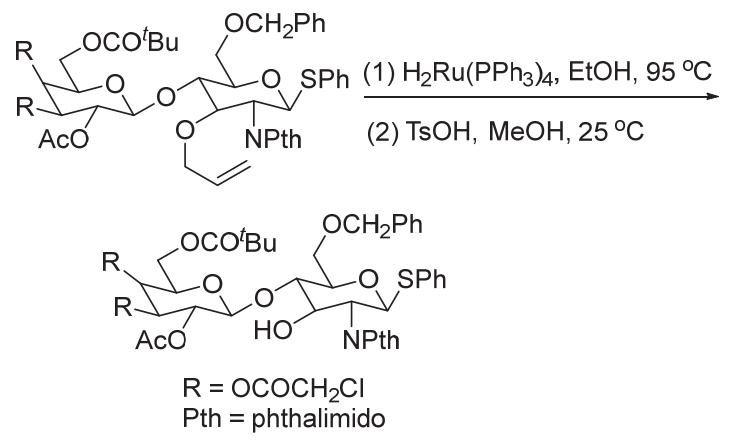

2003 年, Alcaide 等 ${ }^{[83]}$ 报道了使用钓卡宾催化剂催 化的脱烯丙基化反应, 经过异构化方法可以选择性脱去 氮上的烯丙基保护. 反应物在甲苯溶液中加热至回流, 分批加入 Grubbs 卡宾催化剂 $\left[\left(\mathrm{PCy}_{3}\right)_{2} \mathrm{Cl}_{2} \mathrm{Ru}=\mathrm{CHPh}\right]$, 可 以高效地实现底物中氮原子上的脱烯丙基(Eq. 61). 作 者认为是氮原子对钉的配位作用使得催化剂中毒, 所以 不会发生 Grubbs 催化的闭环烯烃复分解反应. 在该反 应条件下, 芳烃和烷烃胺类底物都具有良好的反应活性, 官能团的兼容性也很好, 底物的光学纯度也可以得到保 留; 同时, 当底物中氮、氧原子上同时含有烯丙基保护基 时, 可以选择性地实现氮原子的脱烯丙基化反应.

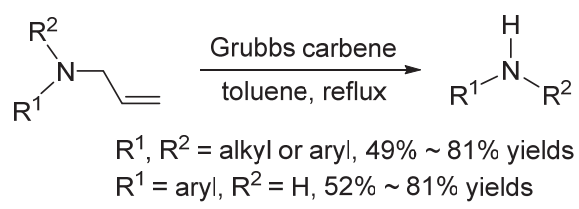

作者对于反应的机理进行了探讨, 通过 ${ }^{1} \mathrm{H}$ NMR 监 测到反应存在烯丙基胺的异构化过程, 生成了中间体烯
胺, 由此推测, 活性催化物种可能不是 Grubbs 卡宾, 而 是金属氢物种. 金属氢物种在底物中氮原子的引导下和 烯烃配位，然后金属氢物种马氏加成到烯烃上，随后发 生 $\beta-\mathrm{H}$ 消除得到更稳定的烯胺, 烯胺水解得到了对应的 胺(Scheme 20).

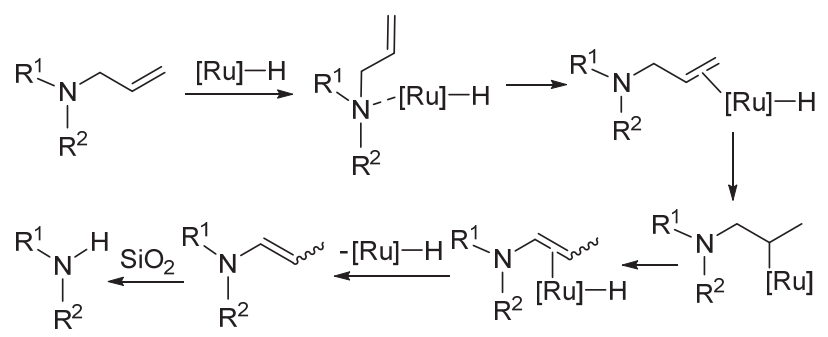

图式 $20\left[\left(\mathrm{PCy}_{3}\right)_{2} \mathrm{Cl}_{2} \mathrm{Ru}=\mathrm{CHPh}\right]$ 催化烯丙基胺异构化脱保护 机理

Scheme 20 Mechanism of $\left[\left(\mathrm{PCy}_{3}\right)_{2} \mathrm{Cl}_{2} \mathrm{Ru}=\mathrm{CHPh}\right]$ catalyzed deallylation of amines via isomerization

2006 年, Alcaide 等 ${ }^{[84]}$ 进一步研究了 Grubbs 卡宾催 化的烯丙基酰胺类化合物的脱烯丙基反应. 同样使用 Grubbs 钉卡宾催化剂在相同条件下反应, 先得到异构 化的产物; 第二步，作者使用 $\mathrm{RuCl}_{3}-\mathrm{NaIO}_{4}$ 催化碳-氮键 断裂, 得到脱去保护的酰胺产物. 反应过程中底物的立 体构型可以保留(Scheme 21).

2004 年, Kitamura 课题组 ${ }^{[85}$ ]报道了四价钌配合物催 化的烯丙基脱除和生成的方法，通过 $1: 1$ 混合 $\left[\mathrm{CpRu}\left(\mathrm{CH}_{3} \mathrm{CN}\right)_{3}\right] \mathrm{PF}_{6}$ 和三苯基膦一锅法反应可以简单地 合成钌 (IV)络合物, 其在甲醇或者其他醇溶剂中, 可以 高效(94\% 100\%)且选择性地催化脂肪烯丙基醚和芳 基烯丙基醚脱烯丙基保护基的反应(Eq. 62). 2006 年，该 课题组 ${ }^{[86]}$ 报道该催化剂在无溶剂或二氯甲烷(DCM)作 为溶剂时，可以实现醇的烯丙基保护过程. 同年，该课 题组 ${ }^{[87]}$ 报道了在该反应体系中额外加入等物质的量的 三氟甲磺酸, 可以成功实现氨基碳酸烯丙酯类化合物的 脱保护. 对于伯胺、吗啉及吡咯烷这样的高亲核性的仲 胺底物都具有良好的催化活性，对苠基、叔丁基和 Fmoc 等保护基也有很好的兼容性.

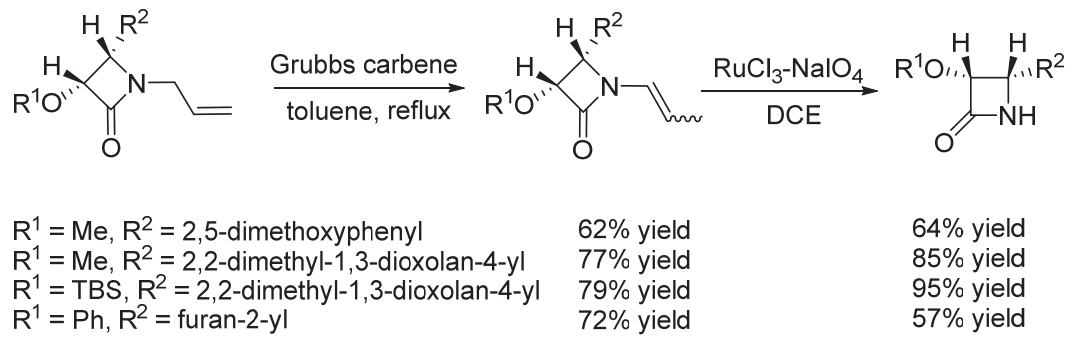

图式 21 Grubbs 卡宾催化的烯丙基酰胺类化合物脱烯丙基反应

Scheme 21 Deallylation of allyl amides catalyzed by Grubbs carbene 


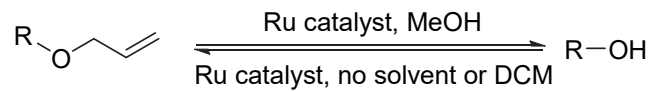

$$
\begin{aligned}
& \mathrm{R}=\mathrm{C}_{6} \mathrm{H}_{5} \mathrm{CH}_{2} \mathrm{CH}_{2} \\
& \mathrm{R}=\text { 2-indanyl } \\
& \mathrm{R}=\mathrm{C}_{6} \mathrm{H}_{5} \mathrm{CH}_{2}\left(\mathrm{CH}_{3}\right)_{2} \mathrm{C} \\
& \mathrm{R}=\mathrm{C}_{6} \mathrm{H}_{5} \\
& \mathrm{R}=\mathrm{CH}_{2}=\mathrm{CHCH}_{2} \mathrm{CH}_{2} \mathrm{CH}_{2} \\
& \mathrm{R}=\mathrm{CH} \equiv \mathrm{CCH}_{2} \mathrm{CH}_{2} \mathrm{CH}_{2}
\end{aligned}
$$

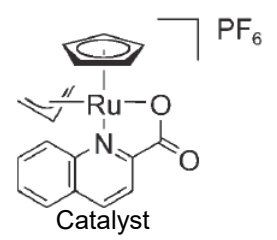

2005 年, Cadierno 等 ${ }^{[88]}$ 报道了在水介质中一锅法脱 去仲胺和叔胺上的烯丙基保护的方法. 作者设计了两种 钉(IV)络合物催化剂, 成功实现了在水溶液中对氮上烯 丙基保护基的脱去(Eq. 63). 该方法对芳环上不同电负 性的取代基都具有较高的反应活性，且对于羰基、甲氧 基和酯基等官能团有很好的兼容性. 通过气相色谱(GC) 监测到了中间体烯胺在水中水解得到丙醛，证实了该反 应经历了异构化的过程.

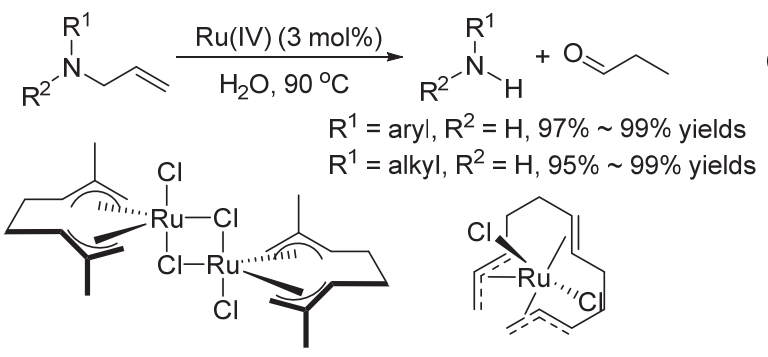

2005 年, Kamijo 等 ${ }^{[89]}$ 报道了使用钉催化剂 $\mathrm{Ru}(\mathrm{CO})-$ $\mathrm{HCl}\left(\mathrm{PPh}_{3}\right)_{3}$ 两步实现烯丙基胺类化合物的脱除烯丙基保 护基的方法. 先使用钉催化剂来使烯丙基碳一碳双键发 生异构化，随后向体系中通入臭氧，可以实现 $N$-烯丙基 键断裂脱保护. 该反应条件对于含有酯基的三唑和四唑 化合物有较好的催化活性. 2008 年, Kajihara等 ${ }^{[90]}$ 报道了 使用相同催化剂实现酰胺的脱烯丙基方法. 使用 $\mathrm{Ru}(\mathrm{CO}) \mathrm{HCl}\left(\mathrm{PPh}_{3}\right)_{4}$ 催化碳一碳双键异构化, 然后臭氧氧 化双键, 再在碱性条件下水解, 高效地脱去了烯丙基保 护基(61\% 95\%)(Eq. 64). 该方法对底物上含有大位阻 基团的底物和多肽类化合物都有很好的反应结果.

$$
\begin{aligned}
& \text { (b) } \mathrm{O}_{3}, \mathrm{DCM},-78^{\circ} \mathrm{C} \\
& \text { then } \mathrm{Me}_{2} \mathrm{~S},-78^{\circ} \mathrm{C} \text { to r.t. } \\
& \text { (c) } \mathrm{Et}_{2} \mathrm{NH}, \mathrm{DCE}, 50^{\circ} \mathrm{C} \quad 95 \% \text { yield }
\end{aligned}
$$

2012 年, Sasmal 等 ${ }^{[91]}$ 报道了光促进的钉催化的氨基 甲酸烯丙酯类化合物的脱保护体系. 该方法使用钉配合 物 $\left[\mathrm{Cp} * \mathrm{Ru}\left(\eta^{6}-\mathrm{pyrene}\right)\right]-\mathrm{PF}_{6}$ 作为光催化剂, 苯硫酚存在 下, 在波长大于 $330 \mathrm{~nm}$ 的紫外光照射下, 可以高效地实 现氨基碳酸烯丙酯类化合物的脱保护生成胺(Eq. 65). 该催化体系在生物细胞环境中也能保持很高的活性, 向
生物细胞中加入无荧光的化合物，与钉催化剂以及苯硫 酚反应可以生成苂光化合物(Scheme 22), 反应 5 10 $\min$ 荧光强度增强了 $35 \sim 70$ 倍, 实现了在生物细胞内的 脱烯丙基反应.
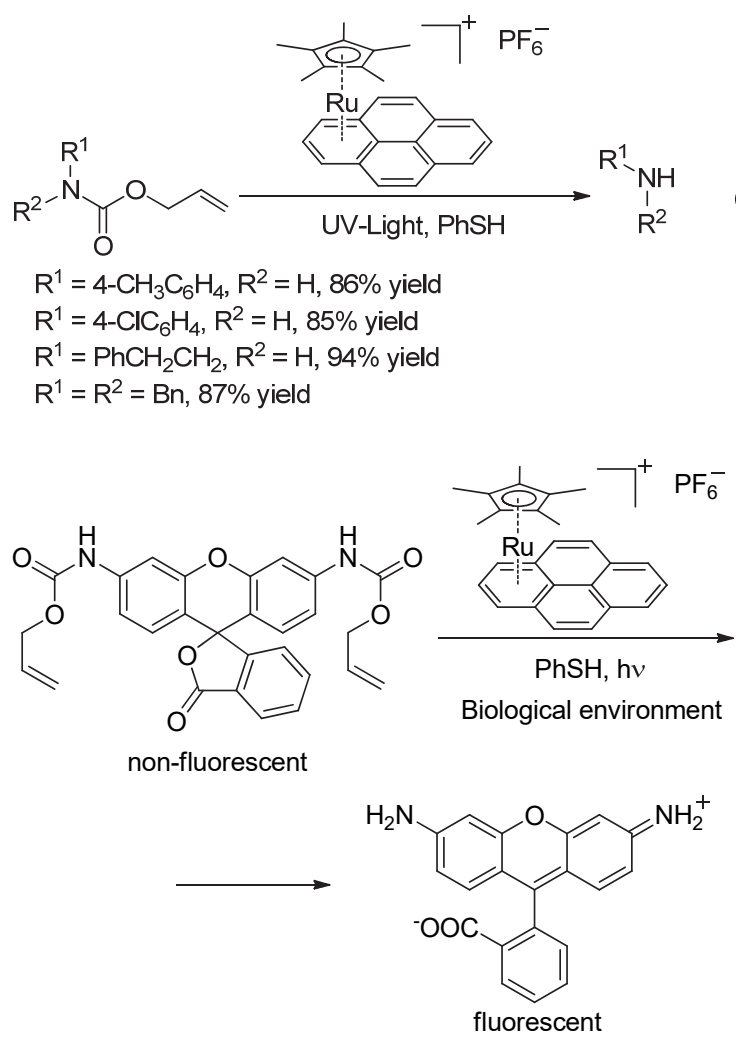

图式 22 生物细胞环境中的钉催化脱烯丙基化反应 Scheme 22 Ruthenium catalyzed deallylation in biological environment

\section{7 镍、铁、铜及钴催化的脱烯丙基反应}

相对于广泛用于烯丙基脱除的贵金属 $\mathrm{Pd} 、 \mathrm{Ru}$ 等，第 四周期过渡金属 $\mathrm{Ni} 、 \mathrm{Fe} 、 \mathrm{Cu}$ 及 $\mathrm{Co}$ 等在这一领域的研 究比较有限.

\section{7 .1 镍催化的脱烯丙基反应}

1989 年, Canoira 等 ${ }^{[92]}$ 在利用邻位卤素取代的苯基 烯丙基醚合成苯并呋喃衍生物的研究中, 发现使用等物 质的量的 $\mathrm{Ni}(0)$ 试剂, 以三苯基膦作为配体，在无水甲苯 或四氢呋喃溶液中反应，可以以 $46 \% \sim 52 \%$ 的收率得到 脱烯丙基产物(Eq. 66).

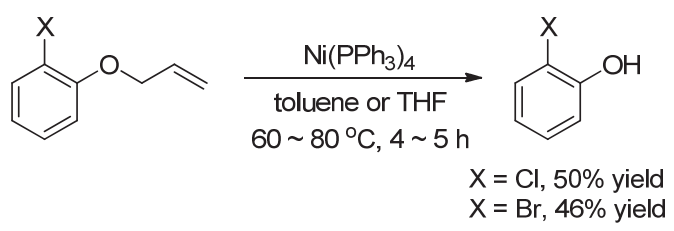

为了拓宽镍催化体系的底物适用范围, 提高官能团 兼容性, 2013 年, Chouhan 等 ${ }^{[93]}$ 也报道了一种使用 1.5 
equiv.镍高效、选择性地脱除芳基上的烯丙基和芐基的 方法. 通过在质子性溶剂中加入 1.5 equiv. 的 $\mathrm{NiCl}_{2}$ 和过 量的还原剂 $\mathrm{NaBH}_{4}, 0{ }^{\circ} \mathrm{C}$ 下很快就能脱除烯丙基和芐基 (Eq. 67), 该方法对于芳基烯丙基醚芳基上的不同官能团 有很好的兼容性, 脂肪烯丙基醚或烯丙基胺也可以保留.

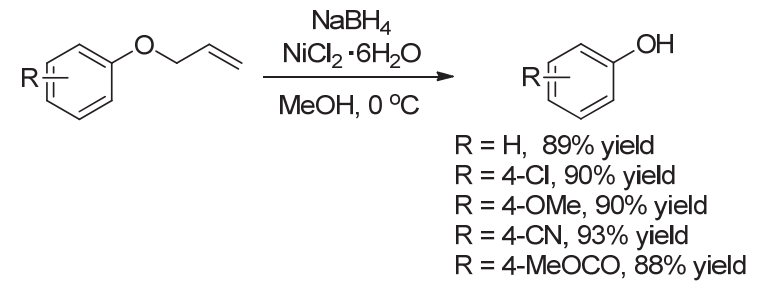

等物质的量镍脱烯丙基化体系取得了很好的效果, 但是使用过多的金属试剂限制了其大规模的生产应用， 并且存在经济环保方面的问题. 1998 年, Ogasawara 课题 组 ${ }^{[94]}$ 报道了使用催化量的镍选择性地脱除氧上烯丙基 保护基的方法. 通过使用催化量 $\mathrm{NiCl}_{2}$ (dppp) 和 1.5 equiv. 的二异丁基氢化铝(DIBAL)在非质子性溶剂中反 应, 可以高产率、高选择性地得到脱保护产物(Eq. 68), 这一体系对于氮原子上的烯丙基脱保护也同样适用(Eq.

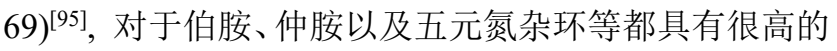
反应活性, 且对于氮上含有的烷基磺酰胺等其他保护基 具有兼容性. 对于酰胺类化合物, 使用三甲基铝代替 DIBAL 之后可以实现较高的转化率(Eq. 70).

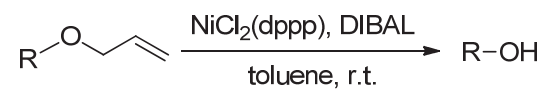

$\mathrm{R}=4-\mathrm{MeOC}_{6} \mathrm{H}_{4}, \mathrm{PhCH}_{2} \mathrm{CH}_{2}, \quad 82 \% \sim 90 \%$ yields (L)-menthyl

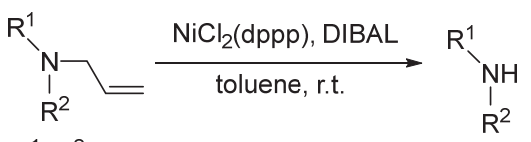

$R^{1}, R^{2}=1,2,3,4$-tetrahydroisoquinolyl, $90 \%$ yield $\mathrm{R}^{1}=$ aryl, $\mathrm{Bn} ; \mathrm{R}^{2}=$ allyl, alkyl, $\mathrm{H}, 69 \% \sim 91 \%$ yield

$$
\begin{aligned}
& \mathrm{R}^{1}=\mathrm{Ph}, \mathrm{R}^{2}=4-\mathrm{MeOC}_{6} \mathrm{H}_{4} \mathrm{CH}_{2}, 92 \% \text { yield } \\
& \mathrm{R}^{1}=\mathrm{R}^{2}=\mathrm{Ph}, 73 \% \text { yield } \\
& \mathrm{R}^{1}=\mathrm{Ph}, \mathrm{R}^{2}=\mathrm{BnCH}_{2}, 78 \% \text { yield }
\end{aligned}
$$

作者对该反应的机理进行了研究，通过控制实验证 明镍是反应发生的必要条件, 在监测反应过程中烯丙基 碳一碳双键上的三个氢原子的化学位移中发现该反应可 能是经历的镍催化的铝氢化加成-消除的过程(Scheme 23).

2005 年, Kamijo 等 ${ }^{[89]}$ 报道了使用镍和格氏试剂体 系实现三唑和四唑类化合物的脱烯丙基化方法(Eq. 82). 在体系中加入 $2 \mathrm{~mol} \%$ 的 $\mathrm{NiCl}_{2}$ (dppe)和化学计量的叔丁

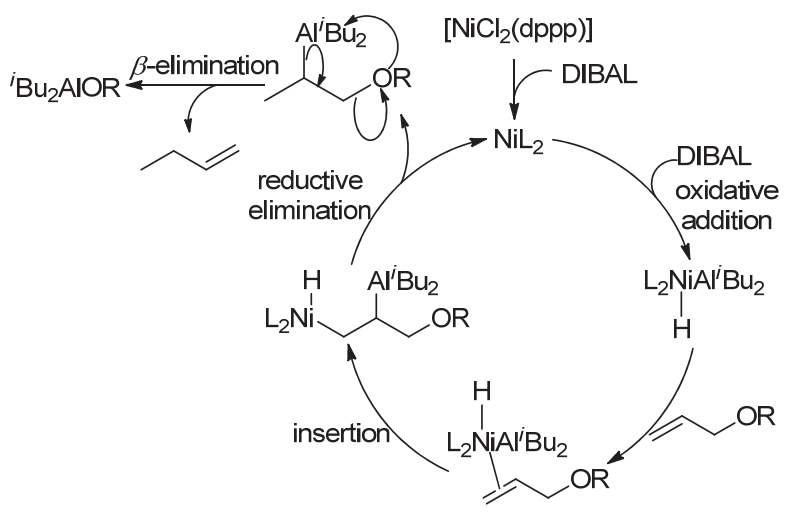

图式 $23 \mathrm{NiCl}_{2}(\mathrm{dppp}) / \mathrm{DIBAL}$ 催化脱烯丙基过程 Scheme 23 Mechanism of $\mathrm{NiCl}_{2}$ (dppp)/DIBAL catalyzed deallylation

基格氏试剂, 在非极性溶剂甲苯中 $0{ }^{\circ} \mathrm{C}$ 搅拌 5 min 即可 高收率地得到产物. 环上带有苯基、烷基、烯丙基三唑 和四唑类化合物以及其他杂环取代的底物都适用，但是 对于含有酯基的底物，反应效果很差.

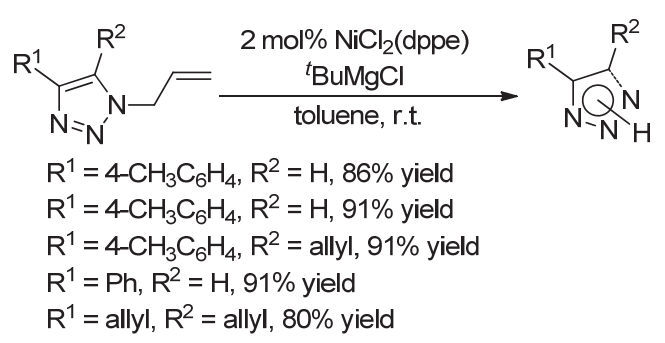

作者认为这个 $\mathrm{Ni}$ 催化体系有两种可能的反应机理. 一种是生成镍氢物种对烯丙基上的双键发生加成，由于 三唑环上氮原子的配位作用, 镍更倾向于加成在靠近三 唑环的一侧，生成中间体 $\mathbf{A}$ ，随后发生 $\beta$ 消除，生成取 代烯烃和 B, B 和格氏试剂发生金属交换, 使镍回到镍 氢状态完成循环, 同时生成 $\mathbf{C}, \mathbf{C}$ 在水中淬灭得到产物 (Scheme 24).

另一种机理可能经历了 $\pi$-烯丙基镍中间体的过程. 由 $\mathrm{NiCl}_{2}(\mathrm{dppe})$ 与格氏试剂反应生成 $\mathrm{Ni}(0)$, 随后和底物 发生氧化加成生成中间体 D, D 再和格氏试剂发生转金 属化，生成 $\mathbf{F}$ 和 $\mathbf{C}$ 以及一分子异丁烯， $\mathbf{C}$ 在水中淬灭得 到产物, $\mathbf{F}$ 发生还原消除回到零价镍(Scheme 25).

此外, 镍催化的脱烯丙基化反应也被应用于药物和 天然产物的有机合成当中残留金属的检测. 2016 年, $\mathrm{Kim}$ 等 ${ }^{[96]}$ 报道将镍催化的脱烯丙基反应应用到药物合 成中残留的镍金属的检测中. 室温下, 在含镍的乙腈/水 $(V: V=3: 7)$ 混合溶液中加入富电子的配体 $\mathrm{PPh}_{3}$ 或 $\mathrm{P}\left(p-\mathrm{CH}_{3} \mathrm{Ph}\right)_{3}$ 以及亲核试剂 $\mathrm{NaBH}_{4}$, 可以高效地实现无 苂光的氨基碳酸烯丙酯类化合物的脱烯丙基生成苂光 化合物, 该方法可以监测到 $5 \sim 10 \mu \mathrm{mol} / \mathrm{L}$ 范围的金属镍 存在(Eq. 72). 


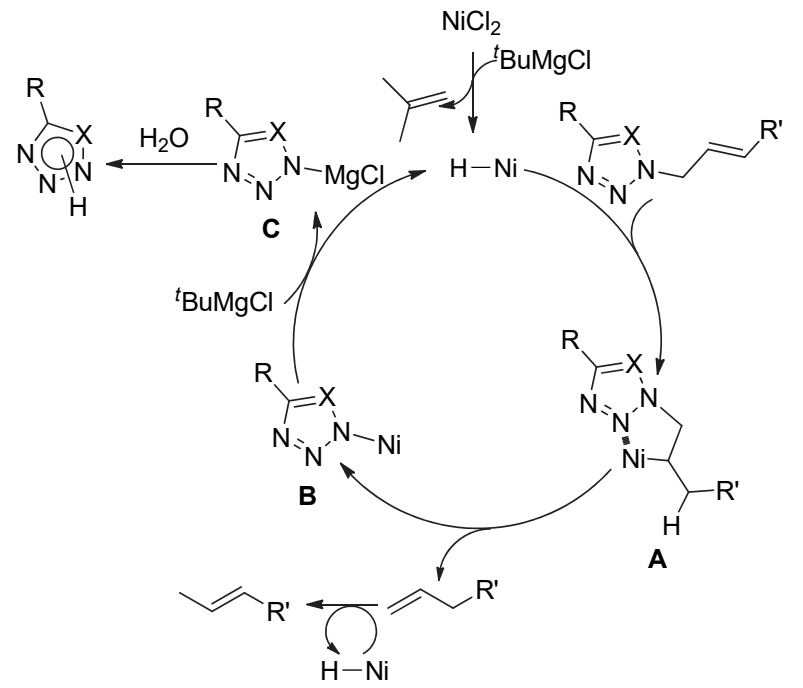

图式 $24 \mathrm{NiCl}_{2}$ (dppe) $/{ }^{t} \mathrm{BuMgCl}$ 催化三唑和四唑类化合物的脱 烯丙基反应可能的机理

Scheme 24 Proposed mechanism of $\mathrm{NiCl}_{2}(\mathrm{dppe}) /{ }^{t} \mathrm{BuMgCl}$ catalyzed deallylation of triazoles and tetrazoles

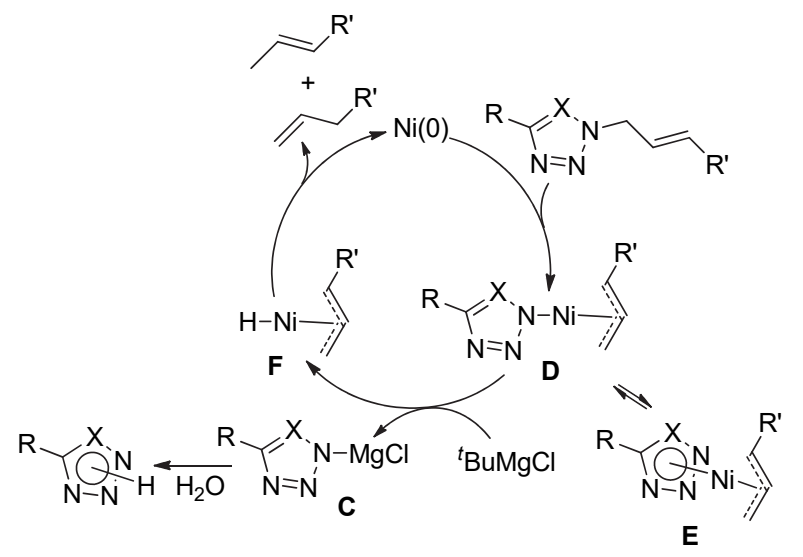

图式 $25 \mathrm{NiCl}_{2}$ (dppe) $/ / \mathrm{BuMgCl}$ 催化三唑和四唑类化合物的脱 烯丙基脱烯丙基反应可能的烯丙基镍中间体的机理

Scheme 25 Proposed mechanism of $\mathrm{NiCl}_{2}(\mathrm{dppe}) /{ }^{t} \mathrm{BuMgCl}$ catalyzed deallylation of triazoles and tetrazoles via $\pi$-allyl nickel

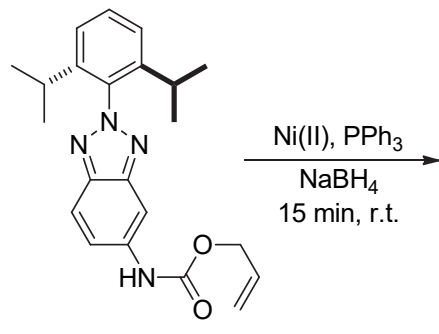

no fluoresence

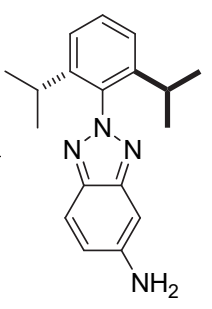

blue fluoresence

\section{7 .2 铁、铜及钴催化的脱烯丙基反应}

2013 年, von Wangelin 课题组 ${ }^{[97]}$ 报道了一种使用 $\mathrm{FeCl}_{2}$ 催化的各种烯丙基醚类和烯丙酯类化合物的快速 脱烯丙基反应. 在二甲苯/四氢呋喃 $(V: V=1: 1)$ 的混 合溶剂中, 加入乙基格氏试剂及 $1 \mathrm{~mol} \%$ 的铁, 可以在
$20{ }^{\circ} \mathrm{C}$ 高效地脱除烯丙基(75\% 100\%)(Eq. 72). 该反应 条件适用于烷基烯丙基醚和芳基烯丙基醚，对于存在卤 素、烯烃、酯、甲硫基、烯丙基胺和茮基的底物有很好 的兼容性, 但是对于烯丙基邻位具有取代基的底物转化 率较低.

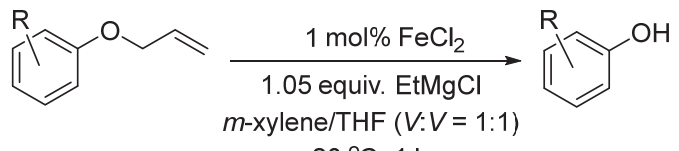

$20^{\circ} \mathrm{C}, 1 \mathrm{~h}$

$$
\begin{aligned}
& R=4-\mathrm{Me}, 97 \% \text { yield } \\
& R=4-\mathrm{F}, 100 \% \text { yield } \\
& R=2-\mathrm{Cl}, 96 \% \text { yield } \\
& R=2-\mathrm{OMe}, 97 \% \text { yield } \\
& R=2-\mathrm{OMe}, 4-\text { Acrylic, } 86 \% \text { yield }
\end{aligned}
$$

1991 年, Iqbal 等[98]报道 $\mathrm{CoCl}_{2}$ 在酰氯存在下, 乙腈 作为溶剂时可以催化烯丙基醚的脱烯丙基反应，得到相 应醇的酰基保护的酯(Eq. 74). 但该反应的选择性较差, 各类醚在该反应条件下都可以发生碳一氧键的断裂. 作 者推测该反应是通过单电子转移来实现的(Scheme 26).

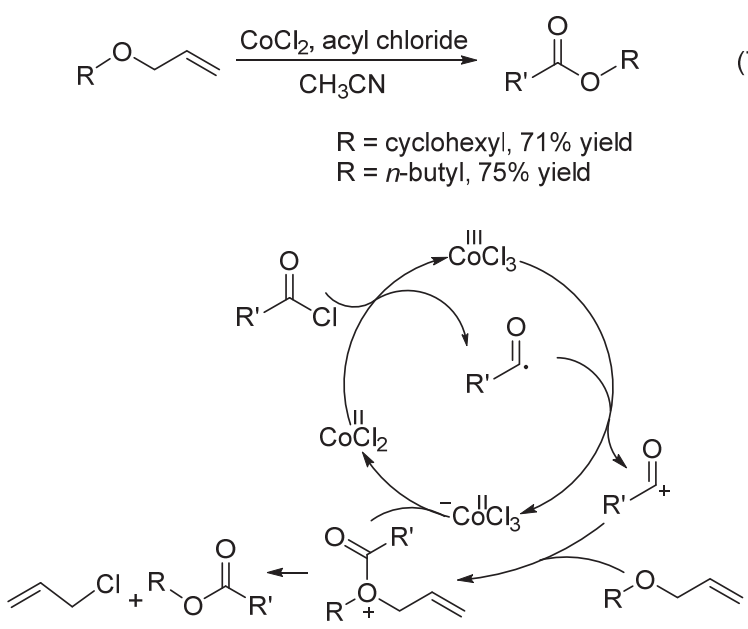

图式 $26 \mathrm{CoCl}_{2}$ 催化脱烯丙基保护机理

Scheme 26 Mechanism of $\mathrm{CoCl}_{2}$ catalyzed deallylation

2017 年, Giedyk 等 ${ }^{[99}$ ]报道了两种使用含钴的维生素 $\mathrm{B}_{12}$ 催化的烯丙基断裂反应，第一种是使用维生素 $\mathrm{B}_{12}$, 二氧化钛作为光氧化还原媒介, 使用波长为 $254 \mathrm{~nm}$ 的 紫外光照射, 高效实现了脱烯丙基过程(Eq. 75); 第二种 方法在维生素 $\mathrm{B}_{12}$ 的催化下, 使用锌/氯化铵作为助催化 剂, $60{ }^{\circ} \mathrm{C}$ 反应得到目标产物(Eq. 76). 两种方法的底物 适应性都很好，而且对于脂肪烯丙基醚的脱烯丙基反应 催化产率也很高.

2017 年, Hemming 等 ${ }^{[100]}$ 报道了一种铜催化的脱烯 丙基反应. 使用催化量的碘化亚铜，加入三苯基膦，以 及化学计量的联砋酸频哪醇酯和甲醇锂, 可以在室温下 高效地脱去烯丙基(Eq. 77), 该反应体系对缺电子的底 

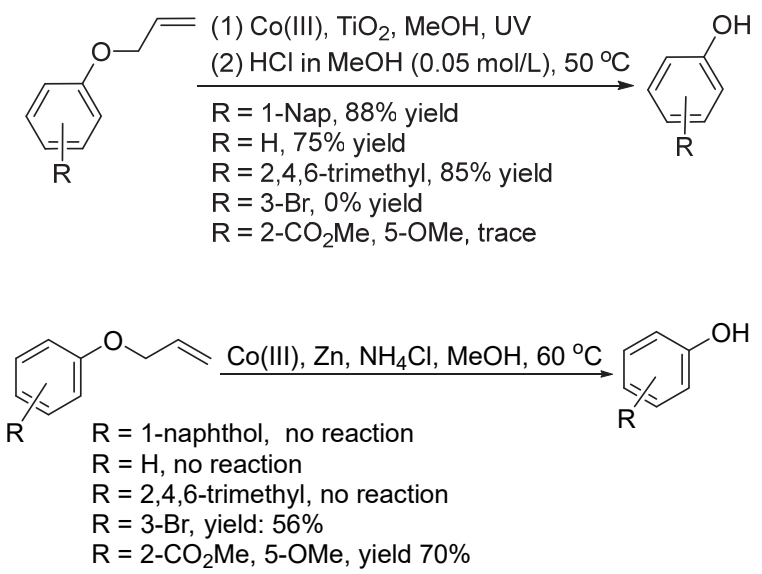

物反应效果比富电子的底物要好, 且对具有大位阻取代 基的底物也有很好的反应活性，但是对烷基烯丙基醚以 及烯丙基胺这些底物反应效果较差. 鉴于该反应条件对 烯丙基胺底物的低反应活性, 可以将该体系应用于肽化 学的选择性脱保护当中, 对于含酪氨酸残基等的二肽, 可以通过控制反应条件实现对氮和氧上的烯丙基选择 性脱保护.
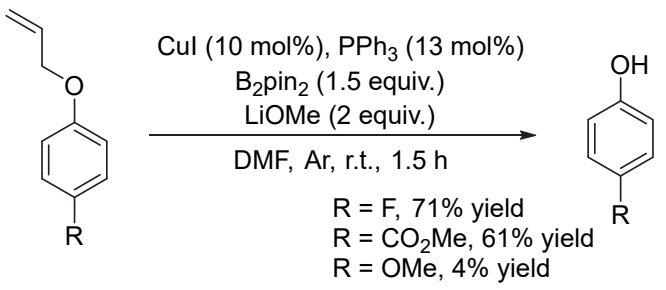

\section{6 通过电化学方法实现的脱烯丙基反应}

1984 年, Morisaki 课题组 ${ }^{[101]}$ 报道以零价钯作为催化 剂, 通过电化学方法实现烯丙基酯脱烯丙基保护. 该方 法适用于芳香烯丙酯、一级/二级脂肪烯丙酯的脱烯丙基 保护, 生成相应的䍨酸(Eq. 78). 具体操作条件是在氩气 气氛中, 使用隔离电解槽, $\mathrm{Pb}$ 作为阴极, $\mathrm{Pt}$ 作为阳极, 在 阴极室内加入烯丙酯底物以及 $5 \mathrm{~mol} \%$ 的 $\mathrm{Pd}\left(\mathrm{PPh}_{3}\right)_{4}$ 催化 剂前体, 并在阴极和阳极室内均加入含有 $\mathrm{Et}_{4} \mathrm{NOTs}$ 的乙 腈作为电解液, 然后以恒定的电流密度进行通电电解.

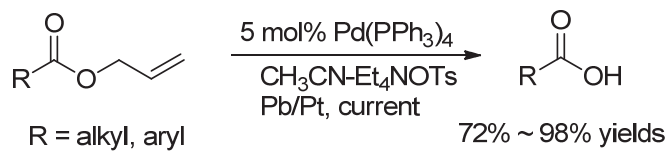

脱烯丙基的反应历程为: 烯丙基酯与零价钯催化剂 发生氧化加成形成烯丙基钯化合物, 烯丙基钯化合物得 到两个电子回到零价钯催化剂继续与烯丙基酯反应，同 时生成烯丙基负离子及脱烯丙基的羧酸根负离子, 其中 烯丙基负离子可以与亲电试剂(三甲基氯硅烷)或质子反
应生成相应的烯烃(Scheme 27).

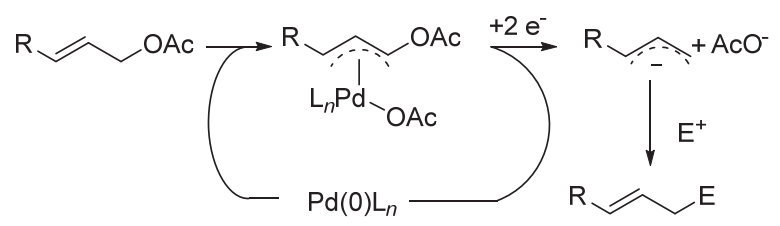

图式 $27 \mathrm{Pd}\left(\mathrm{PPh}_{3}\right)_{4}$ 催化的电化学方法脱烯丙酯的烯丙基保 护的反应机理

Scheme 27 Mechanism of $\mathrm{Pd}\left(\mathrm{PPh}_{3}\right)_{4}$ catalyzed electrochemical deallylation of allyl esters

1992 年, Duñach 课题组 ${ }^{[102]}$ 报道了氯化钐催化的电 化学脱烯丙基保护基的方法. 使用 $\mathrm{SmCl}_{3}$ 作为催化剂, 在 DMF 溶剂中, 镁为阳极, 室温下反应, 可以有效地脱 除酚羟基的烯丙基保护基，如果向体系中额外加入少量 碘化钾, 则对烷基烯丙基醚底物也适用. 但底物上存在 卤素、酯基、醛或酮等官能团时反应选择性较差.

1995 年, 该课题组 ${ }^{[103]}$ 报道了以 $\left[\mathrm{Ni}(\text { bipy })_{3}\right]\left(\mathrm{BF}_{4}\right)_{2}$ 为 催化剂, 通过电解实现脱除烯丙基保护的方法(Eq. 79). 该体系对于芳基烯丙基醚以及芳环上有不同取代基的 底物，都能完全脱除烯丙基保护，相较于之前报道的使 用镧系金属钐催化的电化学脱烯丙基方法, 镍体系更倾 向于发生烯丙基碳一氧断裂，但是对卤代芳烃类的底物 会有副反应发生. 该方法是经历 $\pi$-烯丙基-Ni(II)中间体 的过程进行的. 在恒流条件下, 牺牲镁阳极来使 $\mathrm{Ni}(\mathrm{II})$ 在阴极发生还原反应生成 $\mathrm{Ni}(0)$, 随后 $\mathrm{Ni}(0)$ 和烯丙基 碳-氧键发生氧化加成生成 $\pi$-烯丙基-Ni(II)中间体.

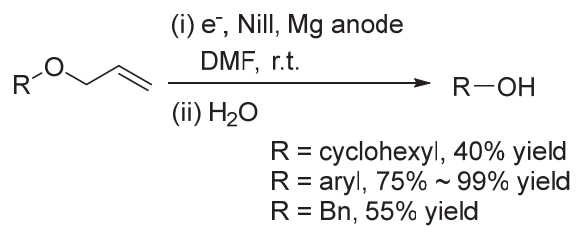

1999 年, Sakamoto 课题组 ${ }^{[104]}$ 报道了一种利用过量 的电解生成的高活性镍，实现烯丙基醚脱烯丙基保护， 得到相应的醇或酚的方法(Eq. 80). 体系可很好地兼容 酯基、氰基、醛羰基、酮羰基、烯基、氯及溴，并且对 着基的其他保护基团，如甲苯磺酰基、苄基、四氢吡喃 也具备很好的兼容性. 但当底物芳香烯丙基醚存在碘代 的情况时，该体系不能有效得到脱保护后的酚产物. 当 反应底物为一级或二级脂肪烯丙基醚时，需使用 8 equiv. 的活性镍物种才能以较高的产率得到相应的脱保 护醇.

$$
\begin{aligned}
& \text { R: alkyl, aryl } \\
& \stackrel{\text { electro-generated Nickel }}{\longrightarrow}
\end{aligned}
$$


具体操作条件为在氩气氛围中, 使用含有 $0.3 \mathrm{~mol} / \mathrm{L}$ $\mathrm{Et}_{4} \mathrm{NBF}_{4}$ 的 $\mathrm{DMF}$ 溶液作为电解液, $\mathrm{Ni}$ 作为阳极, $\mathrm{Pt}$ 作为 阴极, 在未经隔离的电解槽中通以稳定的 $10 \mathrm{~mA} / \mathrm{cm}^{2}$ 的 电流, 在 $0{ }^{\circ} \mathrm{C}$ 电解 $3.5 \mathrm{~h}$, 得到含有高活性物种的 Ni-DMF 悬浮液 (不含大块沉积物). 再将此悬浮液与待 脱保护的底物烯丙基醚在室温下反应，加入 5 equiv.的 $\mathrm{NaOAc}$ 可有效提高脱烯丙基效率.

\section{7 结论与展望}

目前有机合成还不能实现多官能团化合物在没有 保护基存在下的高效、高选择性的转化, 尤其是在天然 产物和药物分子的合成, 因此发展新的官能团保护及脱 保护方法仍然受到广泛的关注. 近年来, 发展了不同的 脱烯丙基保护方法: 碱及还原剂促进、氧化及自由基过 程、路易斯酸促进、碘促进、前过渡金属催化、过渡金 属催化及电化学方法. 其中经历异构化将烯丙基转化为 容易脱除的烯醇醚、烯基胺或烯醇酯类结构是脱烯丙基 重要方法之一, 研究主要对促进烯丙基异构化的试剂或 催化剂进行了改变使反应条件更温和, 提高反应效率及 选择性及对反应底物中的官能团的兼容性. 经过几十年 的研究, 从在强碱高温的条件下发生异构化, 发展到了 室温等条件下过渡金属催化的异构化. 此外, 过渡金属 催化烯丙基化反应的发现大大地促进了过渡金属催化 的脱烯丙基方法的发展. 低价过渡金属催化剂与烯丙基 醚及酯类结构可以通过氧化加成反应发生烯丙基碳杂 键或碳一碳键的断裂, 形成烯丙基金属物种, 然后在不 同的亲核试剂或氢源的作用下，得到相应的脱烯丙基产 物. 通过对催化剂以及亲核试剂的改变, 使脱烯丙基化 反应可以更高效、高选择性地实现, 其中钯催化脱烯丙 基化反应研究得最广泛. 这些脱烯丙基方法不仅被广泛 应用于有机合成中, 最近一些研究将脱烯丙基反应应用 到药物及材料合成中残留金属的检测以及药物在生物 体内的缓释等研究中. 但目前这些高活性、高选择性的 催化剂通常为贵金属催化剂, 其价格较高, 具有一定毒 性, 因此操作简便、廉价、温和、高效且高选择性的脱 烯丙基方法将是未来脱烯丙基反应发展的重要方向.

\section{References}

[1] Greene, T. W.; Wuts, P. G. M., Protective Groups in Organic Synthesis, 3rd ed., John Wiley \& Sons, Inc., New York, 1999.

[2] (a) Weissman, S. A.; Zewge, D. Tetrahedron 2005, 61, 7833. (b) Tang, J.-Y.; Liu, H.-X.; Huang, C.-S. Technol. Dev. Chem. Ind. 2016, 45, 15 (in Chinese).

(唐剑耀, 刘红星, 黄初升, 化学技术与开发, 2016, 45, 15.)

(c) Li, Z. J.; Zhang, S. Q.; Wang, A. B.; Cai, M. S. Acta Chim. Sinica 1998, 56, 1128 (in Chinese).

(李中军, 张三奇, 王安邦, 蔡孟深, 化学学报, 1998, 56, 1128.)

(d) Zhou, Y.; Zhang, L. R.; Zhang, L. H. Acta Chim. Sinica 2001, 59, 1691 (in Chinese).
(周英, 张亮仁, 张礼和, 化学学报, 2001, 59, 1691.)

(e) Deng, X.; Liu, W.; Li, C.; Zhang, Z.; Wang, X.; Liu, J. Chin. J. Org. Chem. 2011, 31, 75 (in Chinese).

(邓喜玲, 刘卫东, 李超, 张志丽, 王孝伟, 刘俊义, 有机化学, 2011, 31, 75.)

[3] (a) Zhang, L.; Wang, Y.; Yu, J.; Zhang, G.; Cai, X.; Wu, Y.; Wang, L. Tetrahedron Lett. 2013, 54, 4019.

(b) Takagi, K.; Fukuda, H.; Shuto, S.; Otaka, A.; Arisawa, M. Adv. Synth. Catal. 2015, 357, 2119.

(c) Bu, X.; Williams, M.; Jo, J.; Koide, K.; Welch, C. J. Chem. Commun. 2017, 53, 720.

[4] Prosser, T. J. J. Am. Chem. Soc. 1961, 83, 1701.

[5] Price, C. C.; Snyder, W. H. J. Am. Chem. Soc. 1961, 83, 1773.

[6] (a) Oltvoort, J. J.; Kloosterman, M.; van Boom, J. H. Recl. Trav Chim. Pays-Bas 1983, 102, 501.

(b) Guibe, F.; M'Leux, Y. S. Tetrahedron Lett. 1981, 22, 3591.

[7] Gevorgyan, V.; Yamamoto, Y. Tetrahedron Lett. 1995, 36, 7765.

[8] Nicolaou, K. C.; Caulfield, T. J.; Kataoka, H.; Stylianides, N. A. J. Am. Chem. Soc. 1990, 112, 3693.

[9] Gigg, R.; Warren, C. D. J. Chem. Soc. C 1968, 1903.

[10] Halkes, K. M.; Slaghek, T. M.; Vermeer, H. J.; Kamerling, J. P.; Vliegenthart, J. F. G. Tetrahedron Lett. 1995, 36, 6137.

[11] Mereyala, H. B.; Lingannagaru, S. R. Tetrahedron 1997, 53, 17501.

[12] Cunningham, J.; Gigg, R.; Warren, C. D. Tetrahedron Lett. 1964, 5, 1191.

[13] (a) Gigg, J.; Gigg, R. J. Chem. Soc. C 1966, 82.

(b) Smith, A. B.; Rivero, R. A.; Hale, K. J.; Vaccaro, H. A. J. Am. Chem. Soc. 1991, 113, 2092.

[14] Yamada, H.; Harada, T.; Takahashi, T. J. Am. Chem. Soc. 1994, 116, 7919.

[15] Lamberth, C.; Bednarski, M. D. Tetrahedron Lett. 1991, 32, 7369.

[16] Pirrung, F. O. H.; Rutjes, F. P. J. T.; Hiemstra, H.; Speckamp, W. N. Tetrahedron Lett. 1990, 31, 5365.

[17] Effenberger, F.; Jäger, J. J. Org. Chem. 1997, 62, 3867.

[18] Kametani, T.; Huang, S.-P.; Ihara, M.; Fukumoto, K. J. Org. Chem. 1976, 41, 2545.

[19] Thomas, R. M.; Mohan, G. H.; Iyengar, D. S. Tetrahedron Lett. 1997, $38,4721$.

[20] Li, C. B.; Ji, X. J.; Zhang, S. M.; Lu, M.; Zhao, Z. X.; Cui, Y.; Xu, Y. L.; Yang, Q. C.; Zhang, W. Q. Chin. Chem. Lett. 2003, 14, 459.

[21] Pawar, B. V.; Lokhande, P. D. Synth. Commun. 2009, 39, 2445.

[22] Mann, F. G.; Pragnell, M. J. J. Chem. Soc. 1965, 4120.

[23] Bailey, W. F.; England, M. D.; Mealy, M. J.; Thongsornkleeb, C.; Teng, L. Org. Lett. 2000, 2, 489.

[24] Sanz, R.; Martinez, A.; Marcos, C.; Fananas, F. J. Synlett 2008, 1957.

[25] Alonso, E.; Ramón, D. J.; Yus, M. Tetrahedron 1997, 53, 14355.

[26] Kariyone, K.; Yazawa, H. Tetrahedron Lett. 1970, 11, 2885.

[27] Choudary, B. M.; Prasad, A. D.; Swapna, V.; Valli, V. L. K.; Bhuma, V. Tetrahedron 1992, 48, 953.

[28] Yadav, J. S.; Chandrasekhar, S.; Sumithra, G.; Kache, R. Tetrahedron Lett. 1996, 37, 6603.

[29] Kumar, P.; Cherian, S. K.; Jain, R.; Show, K. Tetrahedron Lett. 2014, 55, 7172.

[30] Robles Diaz, R.; Rodriguez Melgarejo, C.; Plaza Lopez-Espinosa, M. T.; Izquierdo Cubero, I. J. Org. Chem. 1994, 59, 7928.

[31] Yang, S. G.; Park, M. Y.; Kim, Y. H. Synlett 2002, 492.

[32] Dahlen, A.; Sundgren, A.; Lahmann, M.; Oscarson, S.; Hilmersson, G. Org. Lett. 2003, 5, 4085 .

[33] Escoubet, S.; Gastaldi, S.; Timokhin, V. I.; Ber-trand, M. P.; Siri, D. J. Am. Chem. Soc. 2004, 126, 12343.

[34] Perchyonok, V. T.; Ryan, S. J.; Langford, S. J.; Hearn, M. T.; Tuck, K. L. Synlett 2008, 1233.

[35] Balgotra, S.; Venkateswarlu, V.; Vishwakarma, R. A.; Sawant, S. D. Tetrahedron Lett. 2015, 56, 4289.

[36] Garbers, C. F.; Steenkamp, J. A.; Visagie, H. E. Tetrahedron Lett. 1975, 16, 3753.

[37] Bhatt, M. V.; El-Morey, S. S. Synthesis 1982, 1048. 
[38] Akiyama, T.; Hirofuji, H.; Ozaki, S. Tetrahedron Lett. 1991, 32, 1321.

[39] Sakate, S. S.; Kamble, S. B.; Chikate, R. C.; Rode, C. V. New J. Chem. 2017, 41, 4943.

[40] Nagaraju, M.; Krishnaiah, A.; Mereyala, H. B. Synth. Commun. 2007, 37, 2467.

[41] (a) Konda, S. G.; Humne, V. T.; Lokhande, P. D. Green Chem. 2011, 13, 2354.

(b) Humne, V. T.; Hasanzadeh, K.; Lokhande, P. D. Res. Chem. Intermed. 2013, 39, 585

(c) Humne, V.; Lokahnde, P. Synth. Commun. 2014, 44, 929.

[42] Patil, A. M.; Kamble, D. A.; Lokhande, P. D. ChemistrySelect 2017, 2,8418 .

[43] Satyanarayana, K.; Chidambaram, N.; Chandra-sekaran, S. Synth. Commun. 1989, 19, 2159.

[44] Kadam, S. M.; Nayak, S. K.; Banerji, A. Tetrahedron Lett. 1992, 33, 5129.

[45] Talukdar, S.; Nayak, S. K.; Banerji, A. J. Org. Chem. 1998, 63, 4925.

[46] Lee, J.; Cha, J. K. Tetrahedron Lett. 1996, 37, 3663.

[47] Ohkubo, M.; Mochizuki, S.; Sano, T.; Kawaguchi, Y.; Okamoto, S. Org. Lett. 2007, 9, 773.

[48] Rajakumar, P.; Murali, V. Synth. Commun. 2003, 33, 3891.

[49] Ito, H.; Taguchi, T.; Hanzawa, Y. J. Org. Chem. 1993, 58, 774.

[50] Corey, E. J.; Suggs, J. W. J. Org. Chem. 1973, 38, 3224.

[51] (a) Gent, P. A.; Gigg, R. J. Chem. Soc., Chem. Commun. 1974, 277. (b) Gigg, R. J. Chem. Soc., Perkin Trans. 1 1980, 738.

[52] Sundberg, R. J.; Hamilton, G. S.; Laurino, J. P. J. Org. Chem. 1988, $53,976$.

[53] Ziegler, F. E.; Brown, E. G.; Sobolov, S. B. J. Org. Chem. 1990, 55, 3691

[54] Zacuto, M. J.; Xu, F. J. Org. Chem. 2007, 72, 6298

[55] Boss, R.; Scheffold, R. Angew. Chem., Int. Ed. 1976, 15, 558.

[56] Mori, M.; Ban, Y. Chem. Pharm. Bull. 1976, 24, 1992.

[57] Bieg, T.; Szeja, W. J. Carbohydr. Chem. 1985, 4, 441.

[58] Nakayama, K.; Uoto, K.; Higashi, K.; Soga, T.; Kusama, T. Chem. Pharm. Bull. 1992, 40, 1718.

[59] Mereyala, H. B.; Guntha, S. Tetrahedron Lett. 1993, 34, 6929.

[60] Honda, M.; Morita, H.; Nagakura, I. J. Org. Chem. 1997, 62, 8932.

[61] (a) Ishizaki, M.; Yamada, M.; Watanabe, S.-I.; Hoshino, O.; Nishitani, K.; Hayashida, M.; Tanaka, A.; Hara, H. Tetrahedron 2004, 60, 7973 .

(b) Yamada, M.; Watanabe, S.-I.; Hoshino, O.; Ishizaki, M.; Hayashida, M.; Tanaka, A.; Hara, H. Chem. Pharm. Bull. 2003, 51, 1220 .

[62] (a) Hata, G.; Takahashi, K.; Miyake, A. J. Chem. Soc., Chem. Commun. 1970, 1392

(b) Takahashi, K.; Miyake, A.; Hata, G. Bull. Chem. Soc. Jpn. 1972, 45,230 .

[63] Jeffrey, P. D.; McCombie, S. W. J. Org. Chem. 1982, 47, 587.

[64] Kunz, H.; Unverzagt, C. Angew. Chem., Int. Ed. 1984, 23, 436.

[65] Minami, I.; Ohashi, Y.; Shimizu, I.; Tsuji, J. Tetrahedron Lett. 1985, $26,2449$.

[66] (a) Four, P.; Guibe, F. Tetrahedron Lett. 1982, 23, 1825

(b) Dangles, O.; Guibé, F.; Balavoine, G.; Lavielle, S.; Marquet, A. J. Org. Chem. 1987, 52, 4984.

[67] Roos, E. C.; Bernabe, P.; Hiemstra, H.; Speckamp, W. N.; Kaptein, B.; Boesten, W. H. J. J. Org. Chem. 1995, 60, 1733.

[68] Deziel, R. Tetrahedron Lett. 1987, 28, 4371.

[69] Yamada, T.; Goto, K.; Mitsuda, Y.; Tsuji, J. Tetrahedron Lett. 1987, $28,4557$.

[70] Garro-Helion, F.; Merzouk, A.; Guibé, F. J. Org. Chem. 1993, 58, 6109.

[71] (a) Beugelmans, R.; Bourdet, S.; Bigot, A.; Zhu, J. Tetrahedron Lett. 1994, 35, 4349 .

(b) Beugelmans, R.; Neuville, L.; Bois-Choussy, M.; Chastanet, J.; Zhu, J. Tetrahedron Lett. 1995, 36, 3129.
[72] Lemaire-Audoire, S.; Savignac, M.; Genêt, J. P.; Bernard, J.-M. Tetrahedron Lett. 1995, 36, 1267.

[73] (a) Genêt, J. P.; Blart, E.; Savignac, M.; Lemeune, S.; Paris, J.-M. Tetrahedron Lett. 1993, 34, 4189.

(b) Lemaire-Audoire, S.; Savignac, M.; Blart, E.; Pourcelot, G. Genêt, J. P.; Bernard, J.-M. Tetrahedron Lett. 1994, 35, 8783.

(c) Genêt, J. P.; Blart, E.; Savignac, M.; Lemeune, S.; Lemaire-Audoire, S.; Paris, J.-M.; Bernard, J.-M. Tetrahedron 1994, 50,497

(d) Lemaire-Audoire, S.; Savignac, M.; Pourcelot, G.; Genet, J.-P.; Bernard, J.-M. J. Mol. Catal. A: Chem. 1997, 116, 247.

[74] Seki, M.; Kondo, K.; Kuroda, T.; Yamanaka, T.; Iwasaki, T. Synlett 1995, 609 .

[75] Murakami, H.; Minami, T.; Ozawa, F. J. Org. Chem. 2004, 69 , 4482.

[76] Mora, G.; Piechaczyk, O.; Le Goff, X. F.; Le Floch, P. Organometallics 2008, 27, 2565.

[77] Mao, Y.; Liu, Y.; Hu, Y.; Wang, L.; Zhang, S.; Wang, W. ACS Catal. 2018, $8,3016$.

[78] Enugala, R.; Carvalho, L. C. R.; Marques, M. M. B. Synlett 2010 , 2711.

[79] Martínez-Calvo, M.; Couceiro, J. R.; Destito, P.; Rodríguez, J.; Mosquera, J.; Mascareñas, J. L. ACS Catal. 2018, 8.

[80] Garner, A. L.; Song, F.; Koide, K. J. Am. Chem. Soc. 2009, 131, 5163.

[81] Nieberding, M.; Tracey, M. P.; Koide, K. ACS Sens. 2017, 2, 1737.

[82] Jbara, M.; Eid, E.; Brik, A. Org. Biomol. Chem. 2018, 16, 4061.

[83] Alcaide, B.; Almendros, P.; Alonso, J. M. Chem.-Eur. J. 2003, 9, 5793.

[84] Alcaide, B.; Almendros, P.; Alonso, J. M. Chem.-Eur. J. 2006, 12, 2874.

[85] Tanaka, S.; Saburi, H.; Ishibashi, Y.; Kitamura, M. Org. Lett. 2004, 6,1873

[86] Tanaka, S.; Saburi, H.; Kitamura, M. Adv. Synth. Catal. 2006, 348 , 375.

[87] Tanaka, S.; Saburi, H.; Murase, T.; Yoshimura, M.; Kitamura, M. J. Org. Chem. 2006, 71, 4682.

[88] Cadierno, V.; Garcia-Garrido, S. E.; Gimeno, J.; Nebra, N. Chem Commun. 2005, 4086.

[89] Kamijo, S.; Huo, Z.; Jin, T.; Kanazawa, C.; Yamamoto, Y. J. Org. Chem. 2005, 70, 6389.

[90] Kajihara, K.; Arisawa, M.; Shuto, S. J. Org. Chem. 2008, 73, 9494.

[91] Sasmal, P. K.; Carregal-Romero, S.; Parak, W. J.; Meggers, E. Organometallics 2012, 31, 5968.

[92] Rodriguez, J. G.; Canoira, L. React. Kinet. Catal. Lett. 1989, 38, 351.

[93] Chouhan, M.; Kumar, K.; Sharma, R.; Grover, V.; Nair, V. A. Tetrahedron Lett. 2013, 54, 4540.

[94] Taniguchi, T.; Ogasawara, K. Angew. Chem., Int. Ed. 1998, 37, 1136.

[95] Taniguchi, T.; Ogasawara, K. Tetrahedron Lett. 1998, 39, 4679.

[96] Kim, S.; Jo, J.; Lee, D. Org. Lett. 2016, 18, 4530.

[97] Gaertner, D.; Konnerth, H.; von Wangelin, A. J. Catal. Sci. Technol. 2013, 3, 2541.

[98] Iqbal, J.; Srivastava, R. R. Tetrahedron 1991, 47, 3155.

[99] Giedyk, M.; Turkowska, J.; Lepak, S.; Mar-culewicz, M.; Proinsias, K. O.; Gryko, D. Org. Lett. 2017, 19, 2670.

[100] Hemming, D. S.; Talbot, E. P.; Steel, P. G. Tetrahedron Lett. 2017, 58,17

[101] Torii, S.; Tanaka, H.; Katoh, T.; Morisaki, K. Tetrahedron Lett. 1984, 25, 3207.

[102] Espanet, B.; Duñach, E.; Périchon, J. Tetrahedron Lett. 1992, 33, 2485.

[103] Olivero, S.; Duñach, E. J. Chem. Soc., Chem. Commun. 1995, 2497.

[104] Yasuhara, A.; Kasano, A.; Sakamoto, T. J. Org. Chem. 1999, 64, 4211. 